\title{
UN CONJUNTO DE CAPITELES DE ORIGEN ASIÁTICO EN TARRACO Y BARCINO Reflexiones sobre la importación de elementos orientales en la arquitectura del nordeste de Hispania a partir del siglo II d. C.
}

\author{
POR \\ JAVIER GIMENO
}

\begin{abstract}
RESUMEN
Entre los capiteles compuestos de Tarraco, este artículo distingue un conjunto de fragmentos de zona superior fechables en el siglo II y relacionables con grupos de capiteles minorasiáticos de esa época. A partir de su estudio, y con el complemento de otras piezas de Barcino y de la propia Tarraco, se analizan las corrientes de importación de elementos orientales de decoración arquitectónica en el nordeste de Hispania y se advierte una transformación sustancial de los esquemas durante la época de Adriano.
\end{abstract}

\section{SUMMARY}

This article aims at distinguishing, amongst the composite capitals found at Tarragona, a series of upper zone fragments which should be assigned to the 2nd century A.D. and linked with groups of capitals from Asia Minor of the same period. The study of these fragments, combined with that of other pieces from Barcino and Tarraco itself, leads to an analysis of the trends of import of oriental elements for architectural ornamentation in Northeast Spain and shows a substantial transformation of patterns in Hadrian's period.

Los capiteles compuestos de mármol de Tarraco se han considerado siempre de manera unitaria. Probablemente la presencia de algunos ejemplares relativamente bien conservados, de ca- 
racterísticas homogéneas y cuyas condiciones de estudio permiten una asignación cronológica relativamente fácil y precisa ha ocasionado, en una bibliografía poco escrupulosa, una tendencia generalizada a asimilar a los mismos sin discusión todos los fragmentos menores. Se trata, en concreto, de tres piezas conservadas en el Museo Nacional Arqueológico de Tarragona (en adelante MNAT): principalmente el capitel compuesto hallado en 1884 bajo el Seminario ',$y$ otros dos fragmentos de procedencia hoy no documentada y conservación más parcial ${ }^{2}$. Los tres, en efecto, pueden asimilarse sin problemas a un mismo conjunto, tanto por su morfología como por sus dimensiones. Su estudio tipológico y la procedencia bien determinada del primero han inducido la atribución del conjunto a un momento situado entre finales de la época julioclaudia y principios de la flavia ${ }^{3} \mathrm{y}$, más concretamente, al programa decorativo de la terraza superior de la ciudad alta tarraconense, en cuyo repertorio documental e interpretación se integran sin dificultad ${ }^{4}$.

Sin embargo, ninguna de estas tres piezas, como tampoco los fragmentos menores de hoja de acanto en principio relacionables con ellas, conserva traza alguna de la zona de volutas ni de la decoración del ábaco. Esta observación es importante ya que, recíprocamente, ninguno de los fragmentos conservados de zona superior o jónica de capitel compuesto de mármol, que integran un conjunto relativamente numeroso y muy escasamente estudiado ${ }^{5}$, contiene indicios de la zona de acantos. Ello plantea una situación inicial de disyunción en las piezas conservadas

1 MNAT 114: Hernández Sanahuja, B., Nuevos descubrimientos arqueológicos de Tarragona, BRAH. 6, 1885, pp. 227-238; Hernández Sanahuja, B. Del Arco, A., Catálogo del Museo Arqueológico de Tarragona, Tarragona 1894 (Cátalogo), n.o 114; Hernández Sanahuja, B., Morera, E., Historia de Tarragona, Tarragona 1892, ap. pp. 26-27; Gibert i Olive, A., Temples pagans de la Tarragona romana, Tarragona 1916, p. 13; Puig i Cadafalch, J., L'arquitectura romana a Catalunya, Barcelona 1934 (Puig i Cadafalch), p. 105; Navascués, J. M., Tarragona. IV Congreso Internacional de Arqueología, Barcelona 1929, p. 18; Schulten, A. Tarraco, Barcelona 1948, p. 42; Strong, D. E., Some early examples of the composite capital, JRS 50, 1960, pp. 119-128 (p. 126); Díaz Martos, A. Los capiteles romanos de orden corintio de España y problemas de su estudio, Ampurias 22-23, 1960-1961, pp. 223-237 (p. 231); Heilmeyer, W. D., Korintische Normalkapitelle. Studien zur Geschichte der römischen Architekturdekoration. Heidelberg 1970 (Heilmeyer), p. 140; Hauschild, T., Römische Konstruktionen auf der oberen Stadtterrasse des antiken Tarraco, AEA 45-47, 1972-1974, pp. 3-44 (p. 41); Recasens, M. Los capiteles romanos del Museu Nacional Arqueològic de Tarragona, BA 1979, pp. 43-144 (Recasens) n." 44 (duplicado en Recasens, M., Los edificios públicos de la Tarragona romana a través del estudio de sus capiteles: ensayo cronológico, Papers in Iherian Archaeology, BAR 193, 1984, pp. $321-329$ (p. 326); Gutiérrez, M. A., El capitel compuesto en la Península Ibérica, BSAA 50, 1984, pp. $81-90$ (p. 83); Cortés, R., Gabriel, R., Tarraco. Recull de dades arqueológiques, Tarragona, 1985 (Cortés-Gabriel), n.” 13.

2 MNAT 116 (Catálogo 116; Puig i Cadafalch, p. 333; Recasens 48), con ligera variante en el desarrollo de las flores de los caulículos respecto al anterior, y MNAT 34272 (n. inv. según Recasens 46: probablemente debe identificarse con la pieza n. ${ }^{\circ} 96$ de Catálogo), que ofrece ciertas variantes respecto a la primera de las piezas en el contario y el kymation jónico.

${ }^{3}$ Finales de la época julioclaudia, por semejanza con los capiteles de la Porta dei Leoni de Verona, según Strong, al que sigue Hauschild, y posteriormente Gutiérrez (oper. cit.). Época flavia, aduciendo un paralelismo con los capiteles del arco de Tito, según Heilmeyer, seguido por Recasens. La diferencia entre ambas posibles fechas, no obstante, es demasiado sutil para poder discutirse a partir de argumentos estilísticos basados en modelos romanos y sin otras referencias en Tarraco. Téngase en cuenta que el margen de error resultante sería como máximo de dos o tres décadas.

${ }^{4}$ Hauschild, op. cit.; estado de la cuestión más completo en Alföldy, G. Tarraco, RE Suppl. XV, 1978 , 569-644 (599-603) y Ted'a, El foro provincial de Tarraco, un complejo arquitectónico de época flavia, AEA 62, 1989, pp. 141-191. 

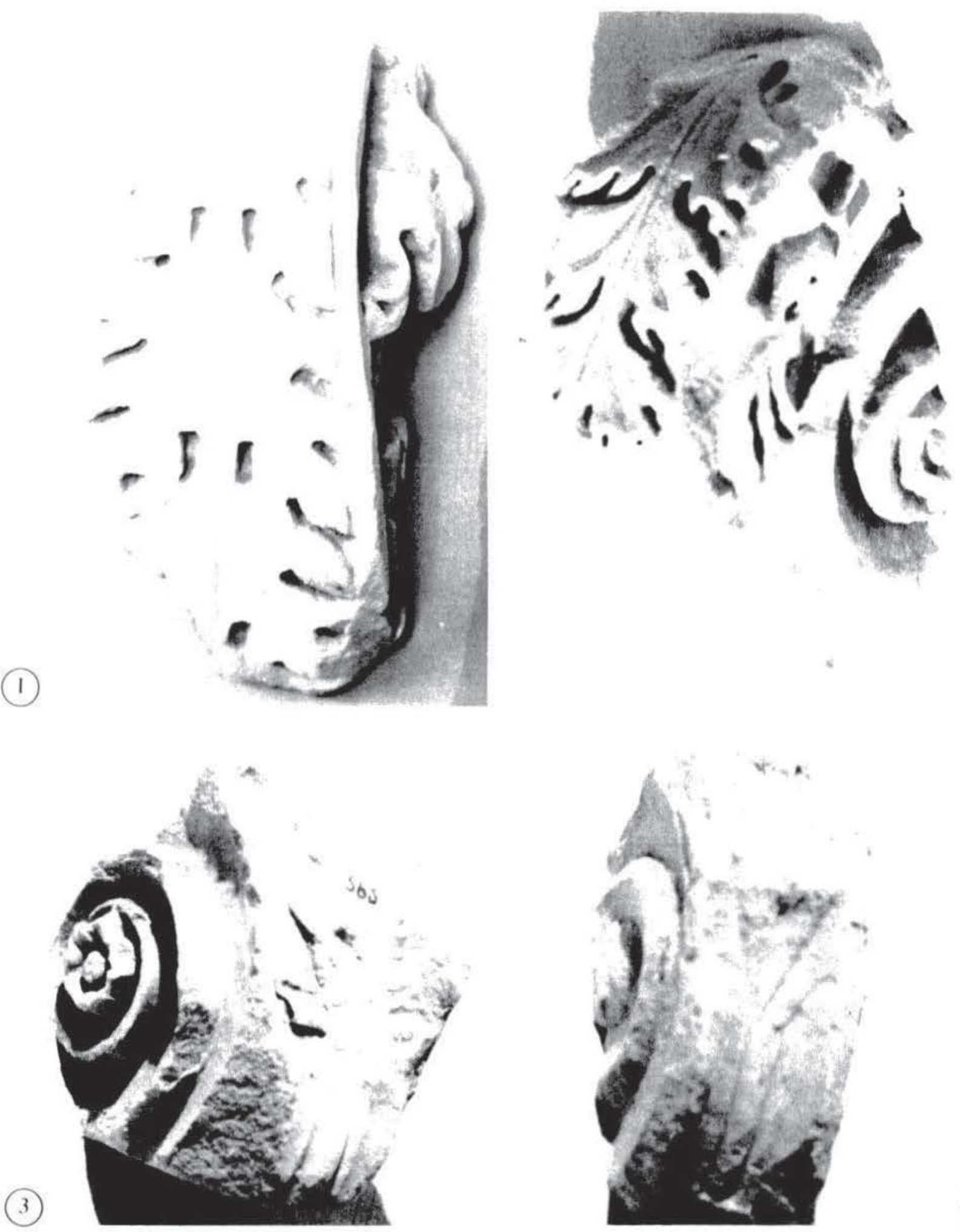

Figura 1.-Tarragona. Fragmentos de capitel compuesto, grupo I, números I a 4. 
que induce tanto a la precaución a la hora de establecer relaciones como a un replanteamiento del estudio, que se intentará abordar en este trabajo y deberá centrarse específicamente en los fragmentos de zona superior. Ello permitirá identificar un nuevo grupo o corriente de la decoración arquitectónica tarraconense, cuya dimensión podrá perfilarse con el análisis de otras piezas de Tarragona y de Barcelona. Para evitar alargar inútilmente el texto, la numeración y los datos de identificación, localización y descripción técnica de las piezas se exponen de forma esquemática en el cuadro anejo, al que se remite para este tipo de documentación.

El conjunto de fragmentos registrados de zona superior de capitel compuesto de mármol se compone de 24 piezas, veintidós de ellas corresponden a volutas o bien incluyen segmentos parciales de canal, volutas, ábaco o varios de estos elementos, y las dos restantes pueden identificarse como flores de ábaco.

Si se observan los fragmentos de voluta, en primer lugar, pueden distinguirse claramente dos grupos. El primero de ellos (núm. 1-16) es el más numeroso y se caracteriza por una mayor uniformidad de soluciones decorativas y, en general, por una tendencia más desarrollada a la profusión ornamental. Por otra parte, se compone exclusivamente de volutas, lo que facilita una descripción conjunta. Las espirales, de cuatro vueltas visibles, ofrecen un trazado geométrico en general uniforme - si bien en este punto cabe una precaución dada la conservación parcial de todas ellas-y preciso. La sección - cónica- es cóncava, con el borde definido por un listel. La nota más destacable, sin embargo, viene dada por la decoración de tipo vegetalizante, que responde a la intención de recubrimiento decorativo. Se observa la presencia de zarcillos de acanto en el interior del canal $^{6}$, de una flor pentapétala que destaca el polo de la espiral y de una hoja, identificable como de caducifolia, que recubre el cojinete o banda determinada en volumen por las volutas ${ }^{7}$. El balteo - bajo esta hoja - se compone de un bocel enmarcado a ambos lados por un caveto y un listel. Estas formas pueden observarse con detalle en los fragmentos números $6,7,8$ y 9 , y parcialmente en los números 3 y 4 .

Las variantes tipológicas principales se manifiestan, como es lógico, en los motivos vegetales, es decir, los zarcillos de acanto y más concretamente las terminaciones de éstos. Se registran formas de cáliz y palmeta - fragmentos números 6,7 y 8 -, cáliz y semipalmeta — número 2-, palmeta sin cáliz - número 11 - o bien desarrollo no en forma propiamente de zarcillos sino de hojas de foliolos pendientes — números, 9,10 y 14; relacionado con la semipalmeta, sin cáliz, números 11 y 15 - Las flores pentapétalas de los polos de las espirales presentan una mayor uniformidad, y las hojas que recubren los cojinetes muestran diferencias debidas sobre todo a diferentes manos o al grado de acabado.

${ }^{5}$ A título de ejemplo, el catálogo de Recasens recoge solamente 9 de estos fragmentos cuando pueden localizarse como mínimo 19 en el MNAT.

${ }^{6}$ No se observa en los fragmentos números 3,4 y 5 , probablemente por corresponder a sectores de la espiral donde el zarcillo ya no llega - es decir, la zona en general bajo la recta horizontal que pasa por el polo-; ya que los demás elementos visibles sí corresponden a los del resto de la serie.

${ }^{7}$ Esta banda en efecto corresponde a la transformación topológica de la forma del cojinete de los capiteles jónicos al aplicar la voluta en todas las caras del capitel. Se mantiene por tanto esta denominación, así como la de balteo para su elemento central. Esta observación adquirirá especial interés en el estudio de los fragmentos del segundo grupo. Para la terminología de estos elementos en el capitel jónico cf. Bingöl, O. Das ionische Normalkapitell in hellenistischer und römischer Zeit in Kleinasien, Tübingen 1980 (Bingöl), p. 49. 

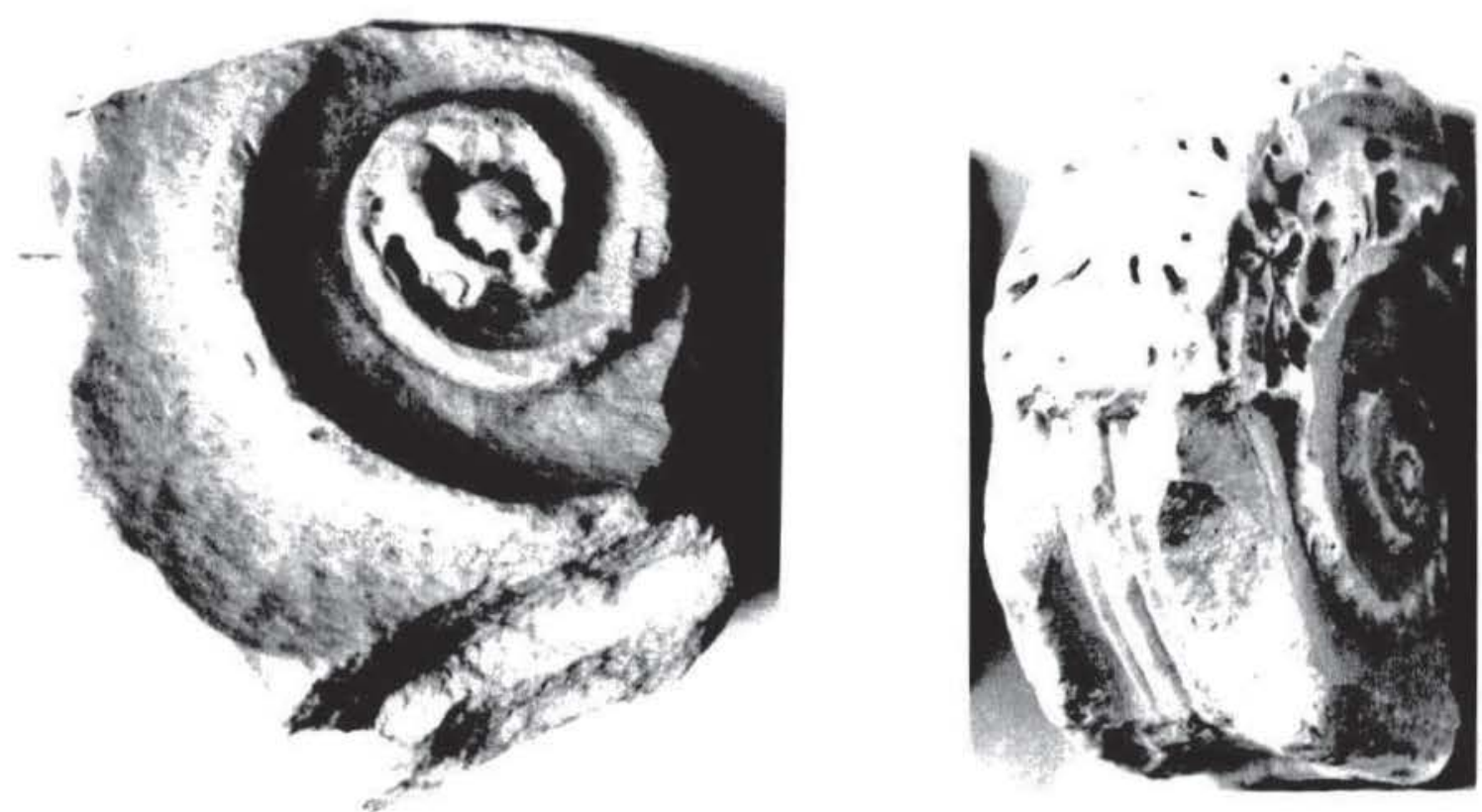

(6)

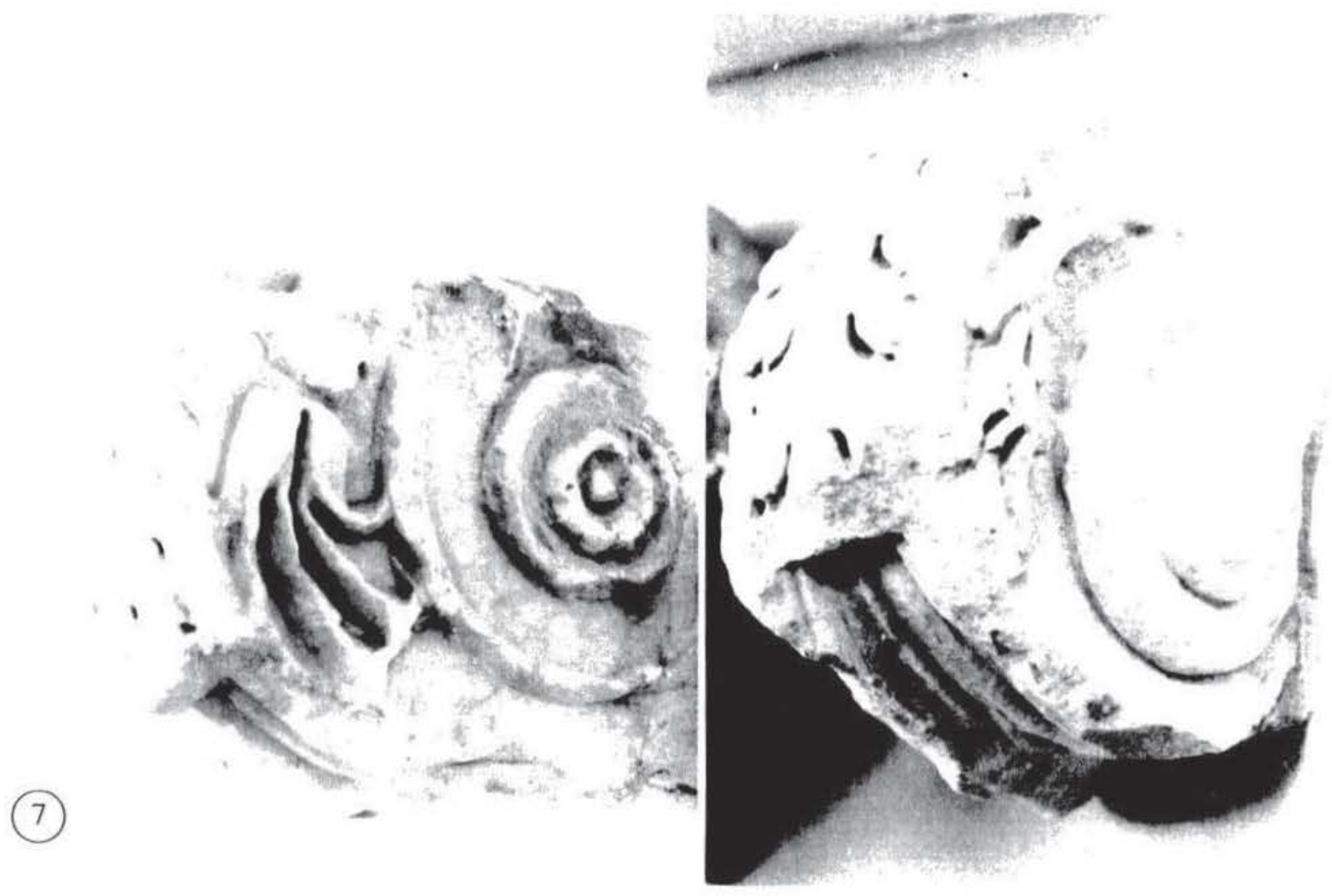

Figura 2.-Tarragona. Fragmentos de capitel compuesto, grupo I, números 5 a 8 . 
Respecto a éste, puede observarse la obtención de los contornos mediante trépano, no siempre perpendicular a la superficie -apreciable claramente en los fragmentos números 1, 2, 5 (flor pentapétala inacabada), 8,11 y $12-$ y una definición en general de las formas mediante un modelado suave acompañado de incisiones ligeras, aunque no faltan los relieves más destacados en volúmenes alabeados — fragmentos números 7,8 y 15 - Se observan algunas diferencias, por último, en las dimensiones. Algunos ejemplares pueden plantear por ello la posibilidad de varios conjuntos o por lo menos varias unidades decorativas. Destacan, por ejemplo, los fragmentos números 10 y 16 en grosor o, en diámetro exterior de la espiral, dentro de los escasos ejemplares en que se documenta este dato, el número 6.

Salvo estas diferencias, no obstante, el conjunto presenta una homogeneidad general destacable y parece corresponder, si no a un mismo momento y programa decorativo, por lo menos a una evolución bastante restringida de una misma corriente o incluso taller.

Sus características, por otra parte, pueden asignarse de manera bastante precisa. Dentro de la propia Tarraco, que evidentemente proporcionaría los datos de mayor utilidad, es difícil encontrar piezas relacionables con ellas salvo los capiteles compuestos mencionados en primer lugar. Como únicos indicios pueden reconocerse formas de modelado equivalentes a las descritas en frisos fechados entre las épocas julioclaudia y flavia ${ }^{8}$, y la aplicación de tipos de cáliz con modelos análogos a los registrados en fragmentos de kyma lésbico fechables en el mismo período $^{9}$ o de phalera con una asignación más concisa a la época flavia ${ }^{10}$. En un contexto más general, el tipo de voluta se ajusta de manera bastante precisa a la que se utiliza en los capiteles compuestos romanos de la época flavia considerada en sentido amplio. Dentro de ella, sin embargo, debe observarse que, respecto a la obligada referencia de los capiteles del arco de Tito,

${ }^{*}$ En concreto en la obtención de las hojas y motivos vegetales: frisos MNAT 104, 105 (Catálogo 104 y 105; Albertini, E., Sculptures antiques du Conventus Tarraconensis, AIEC 4, 1911-1912, pp. 323-474, n. 119; Puig i Cadafalch, p. 206; Recasens i Comes, J. M., La ciutat de Tarragona I, Barcelona 1966, p. 220; Cortés-Gabriel, n. ${ }^{28}$; también n." 27 respecto a otros fragmentos desaparecidos; Janon, M., Le décor architectonique de Narbonne. Les rinceaux, París, 1986, p. 39), fechables en época julioclaudia, o MNAT 112, 113,310, otros fragmentos sin n." inv. y los del claustro de la Catedral (Catálogo 112, 113 y 310; Albertini 121; Hauschild, op. cit., p. 43; Cortés-Gabriel, n. ${ }^{\circ}$ 14) correspondientes a principios de la época flavia.

${ }^{9}$ En fragmentos inéditos de cornisa y de marcos con kyma de arco trilobulado conservados en el MNAT $\sin n .^{\circ}$ inv. Este tipo de kyma (Bügelkymation en la terminología de Wegner, M., Ornamente kaiserzeitliche Bauten Roms. Soffitten, Köln-Graz 1957, pp. 52-64, tipo A en la de Strong, D. E. Late Hadrianic Architectural Ornament in Rome, PBSR 21, 1953, pp. 118-151, o kymation trilobato en la de Bertoldi, M. E., Ricerche sulla decorazione architettonica del Foro Traiano, Roma, 1962, p. 23) se adopta en Tarraco según modelos romanos de época julioclaudia y parece mantenerse sin variaciones significativas hasta un momento bastante tardío.

${ }^{10}$ Se trata asimismo de fragmentos inéditos y $\sin \mathrm{n} .{ }^{\circ}$ inv. del MNAT, asimilables a los conocidos con representación de Zeus Amón. La fecha fue establecida por García y Bellido, A., Esculturas romanas de España y Portugal, Madrid, 1949, n. 416, y no se ha replanteado posteriormente salvo algunas cuestiones de detalle: cf. Koppel, E. Die römischen Skulpturen von Tarraco, Berlín, 1985, con algunas observaciones marginales al respecto. Su aplicación arquitectónica fue propuesta por Hauschild, op. cit., p. 43 a partir del modelo establecido por Zanker, P. Forum Augustum, Tübingen, 1969, p. 13-14, y tampoco se ha replanteado; cf. más recientemente Hauschild, T., Excavaciones en Tarraco, en Arqueología de las ciudades modernas superpuestas a las antiguas, Zaragoza, 1983, Madrid, 1985, pp. 173-177 (p. 176), o el trabajo mencionado de Ted'a. 

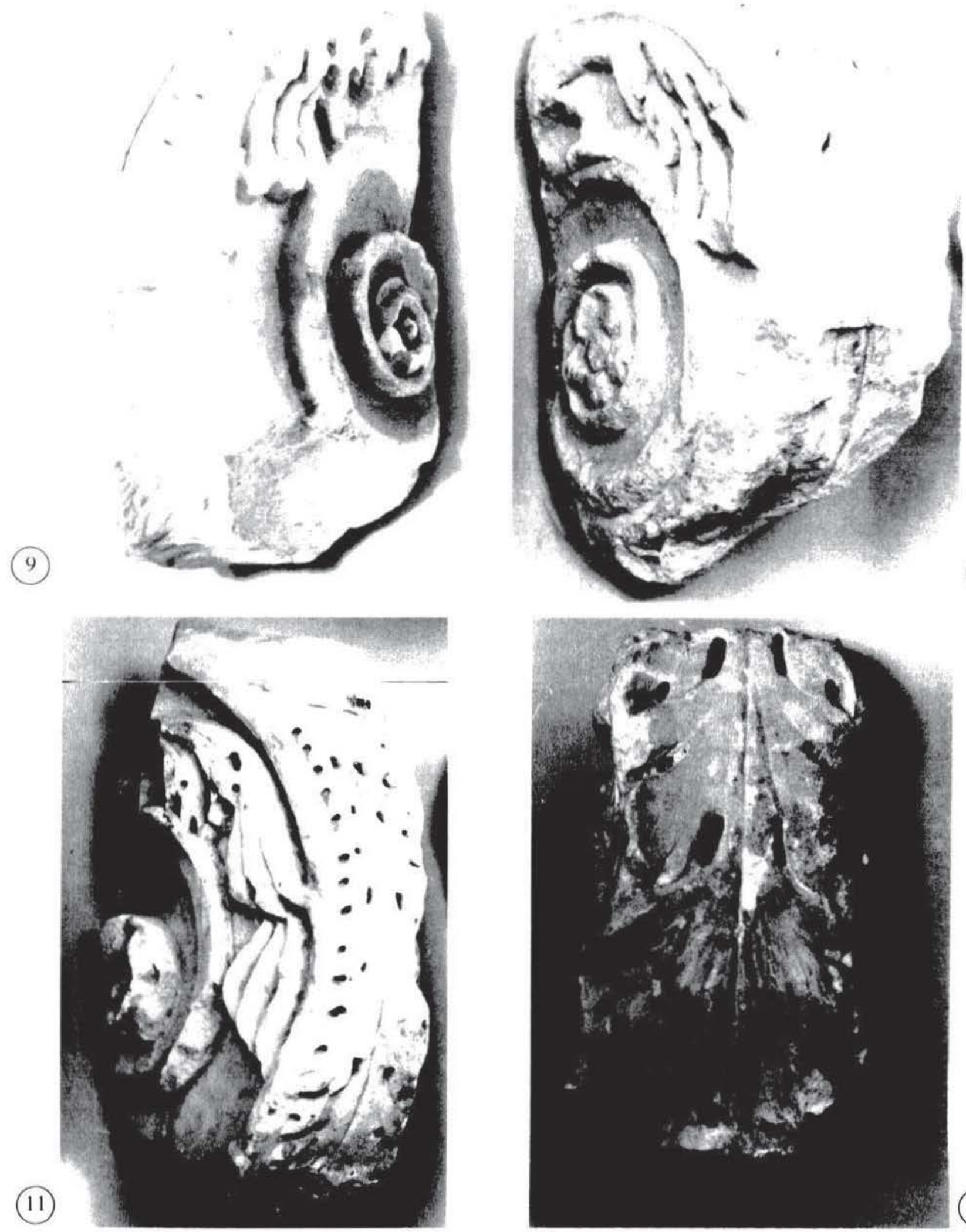

Figura 3,-Tarragona. Fragmentos de capitel compuesto, grupo I, números 9 a 12. 
el grado de recargamiento observable en la composición y relleno de las volutas tarraconenses es significativamente más moderado. El recorrido de los zarcillos, de un cuadrante de vuelta de la espiral en Tarraco y de una vuelta completa en el arco de Tito, constituye un dato expresivo. Este particular puede relacionarse con las observaciones de Strong acerca del capitel MNAT 114 que motivan su propuesta de adscripción a la época julioclaudia ", y viene a constituir por tanto un nuevo elemento de afinidad con éste. Caben sin embargo dos observaciones. En primer lugar, recordar las precisiones, más recientes, de Pfanner sobre la fecha del arco de Tito y la vinculación de sus características a una etapa subsiguiente, representada esencialmente por el arco de Trajano en Benevento ${ }^{12}$. Ello viene a reafirmar la relatividad del primero como referencia, sobre todo respecto a Tarraco — que puede acentuarse si se advierte la analogía de los ejemplares tarraconenses con capiteles compuestos flavios del Palatino, que Pfanner, sin embargo, vincula más directamente a los del arco-y, en segundo término, de las observaciones mencionadas de Strong. Por otra parte, se debe insistir en la inoperatividad de las dataciones estilísticas en este punto y esta escala, aspecto que subraya especialmente Pfanner y que en este caso se ve agravado por tratarse exclusivamente de fragmentos de voluta sin la referencia, siempre más segura, del acanto: de ahí también que resulte útil poder documentar técnicas asimilables en fragmentos tarraconenses aunque sean escasos y de otro tipo. En síntesis, los únicos hechos que parecen perfilarse con cierta verosimilitud en este primer grupo de volutas, aparte de la homogeneidad del conjunto, son la posibilidad de asimilación al capitel del Seminario (MNAT 114) y equivalentes y un carácter estilístico concordante con las corrientes romanas de época julioclaudia o flavia y, dentro de ellas, con un estadio formalmente previo a la eclosión del barroquismo flavio que supone el arco de Tito, sin que ello implique necesariamente una fecha anterior, por otra parte probable dadas las analogías observadas. Las variantes parecen responder, como se ha apuntado, a diferentes manos dentro de un mismo taller o a la evolución de una corriente que mantiene sus constantes, hecho que no es infrecuente en Roma: nótese la conservación, hasta bien entrado el siglo II, de elementos decorativos característicos de la época flavia que conviven con la adopción de formas nuevas ${ }^{13}$. Pero es probable que por lo menos la mayoría de los ejemplares corresponda al mismo programa decorativo.

Se documenta la procedencia de 5 de las piezas - números 1 a 5 . En todos los casos corresponde a la ciudad alta y, dentro de ella, salvo el número 5 , se relaciona directamente con la terraza superior. Ello insiste una vez más en la vinculación a los capiteles mencionados y, en general, a las piezas correspondientes al programa protoflavio o flavio de decoración en gran escala de la zona, al que por lo menos una mayoría puede atribuirse sin problemas. Vienen a constituir pues un elemento más en la interpretación del mismo.

El grupo descrito, testimonio de una forma de voluta adoptada en una fase determinada de la decoración de las terrazas de la ciudad alta, va a constituir una referencia obligada, y de ahí

"Respecto a los capiteles compuestos de la Porta dei Leoni de Verona puede observarse que, si la hoja de acanto, elemento a este respecto fundamental, responde mejor a estos esquemas, la voluta no ofrece una relación tan precisa en el modelado, aunque sí en el modelo aplicado: cf. Kähler, H. Die römischen Stadttore von Verona, JDAI 50,1935, pp. 138-197 (p. 159).

12 Pfanner, M., Der Titusbogen, Mainz, 1983 (Pfanner), pp. 91-92.

13 Leon, C., Die Bauornamentik des Trajansforums und ihre Stellung in der früh-und-mittelkaiserzeitlichen Architektur-Dekoration Roms, Wien, 1971 (Leon), pp. 236-238 y, más generalmente, pp. 258280 . 
la necesidad de haber delimitado sus términos. El interés de este trabajo, sin embargo, se centra principalmente en el segundo grupo, que comprende el resto de las piezas e incluye, como se verá a partir del análisis, todos los fragmentos que no corresponden a volutas. En este caso no existen elementos conservados de zona de acantos que puedan proporcionar hipótesis de relación, lo que dificulta las referencias. Por otra parte se aprecia una heterogeneidad bastante más acusada. Ello y la ausencia de bibliografía aconsejan una descripción más individualizada. Por último, debe observarse que la documentación sobre la procedencia de las piezas en este segundo grupo es absolutamente nula.

El primero y más llamativo de los fragmentos (núm. 17) contiene una voluta y el correspondiente ángulo del ábaco ${ }^{14}$. En contraste con los ejemplares anteriores, la decoración es esencialmente simplificada. El cojinete, en primer lugar, se recubre con una hoja de tipo caducifolio más prolongada que las observadas en el primer grupo y a su vez diseñada y modelada de manera esencialmente distinta: el nervio central va esta vez en relieve, $y$ los foliolos vienen determinados por una delimitación del contorno precisa pero en escaso relieve y con el trépano fino apuntado únicamente - por lo menos en el resultado final-en los puntos esenciales. Se observa por otra parte el arranque de un motivo exento que se sitúa entre la voluta y el ángulo del ábaco. Bajo la hoja, el balteo es de doble cordón. no enmarcado sino por la superficie resultante de la geometría de la propia voluta. Es decir, recupera en cierto modo los esquemas decorativos del balteo del capitel jónico canónico, trasponiéndolos a una estructura de volutas en las cuatro caras.

La voluta, por su parte - equivalente en ambos lados-presenta un canal liso, salvo en todo caso en la salida de la espiral, donde se aprecia el origen de un motivo identificable, por su posición, con la palmeta de ángulo característica de los capiteles jónicos ${ }^{15}$. El borde es un simple
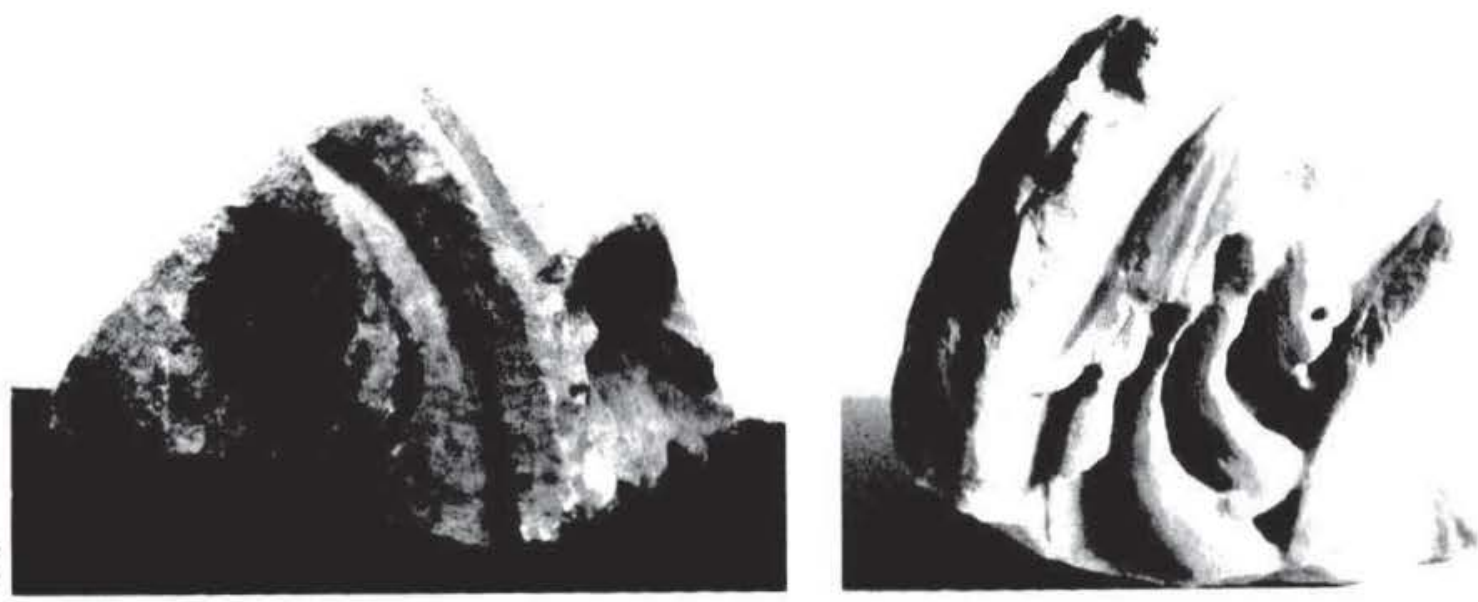

Figura 4.-Tarragona. Fragmentos de capitel compuesto, grupo 1, números 14 y 15.

14 Catálogo 136; Puig i Cadafalch, p. 333, la hace corresponder al capitel compuesto MNAT 108; Recasens, 49 , duda de esta correspondencia, pero no atribuye una fecha ni estudia la pieza.

is Adoptamos el término de la traducción de Zwickelpalmetten: Bingöl, p. 40. 
listel enmarcado a su vez por un sublistel. El polo de la espiral viene marcado por un fino orificio que constituye el centro de un círculo plano en una de las caras y de un ligero casquete esférico en la otra. El ábaco, por su parte, presenta una decoración de kyma lésbico, en una versión muy simple ${ }^{16}$, enmarcado superiormente por una banda.

La simplificación de motivos y las características generales observadas deben encuadrarse en las corrientes de revalorización del orden jónico en sus formas helenísticas, que tiene lugar en el siglo II. La presencia de volutas de este tipo se documenta fácilmente en ejemplares jónicos del Foro de Trajano en Roma ${ }^{17}$, con analogía bastante directa, o, en modelos compuestos, en ejemplares específicamente minorasiáticos del siglo II y, en concreto, en el grupo que Heilmeyer reconoce como escuela pergaménica y efesíaca ${ }^{18}$, cuyo esquema decorativo reproduce fielmente el ejemplar tarraconense. La decoración del ábaco en kymation lésbico aparece también en ejemplares jónicos adrianeos de Roma y sobre todo de Tívoli ${ }^{19}$, probablemente influidos por las mismas corrientes. A este respecto es interesante observar, en los capiteles jónicos documentados por Bingöl en Asia Menor - uno de los pocos repertorios suficientemente completos y útiles en este punto- que el kyma lésbico se usa, con una profusión significativa, o bien en época helenística - siglo II a. C. - o ya en el siglo II d. C. a partir de Adriano ${ }^{20}$. El tipo de

16 Del tipo Scherenkymation en la nomenclatura de Wegner, op. cit. Corresponde al Scheren-GlattBlattkyma de Pfanner, p. 24, o al tipo D de Strong, PBSR 21, 1953, p. 121.

${ }_{17}$ Gusman, P., L'art décoratif de Rome, de la fin de la République au IVème siècle. París 1912-1914, n. ${ }^{\circ} 11$,; Heilmeyer, p. 170. A pesar de ello la asignación a un capitel compuesto es segura dada la geometría tridimensional de la pieza y en concreto del ábaco.

${ }_{18}$ Heilmeyer, loc. cit. y pp. 93-94. Otros ejemplares en Éfeso, cf. Bammer, A., Elemente flavisch-trajanischer Architekturfassaden aus Ephesos, JÖAI 52, 1978-1980, pp. 67-90 (pp. 88-89); también Strocka, V. M., Wechselwirkungen der stadtrömischen und kleinasiatischen Architektur unter Trajan und Hadrian, IM 38, 1988, pp. 291-307 (p. 295), presenta un capitel compuesto correspondiente a la refracción de la Biblioteca de Celso con un tipo de voluta muy similar, si bien el ábaco se integra más bien en el tipo de los ejemplares siguientes. En la basílica A de Afrodisias, Heilmeyer, p. 169; un ejemplar más reciente en Erim, K. T., Recent work at Aphrodisias 1986-1988, en Aphrodisias Papers, Ann Arbor 1990, pp. 9-36 (p. 15). No obstante, la publicación de los elementos arquitectónicos de Afrodisias es aún bastante incompleta. En Mileto se observa una voluta similar en un capitel de características probablemente correspondientes a una fase anterior y que puede señalar una tradición al respecto: Müller-Wiener, W., et al. Milet $1981, I M 32,1982$, pp. 5-29 (pp. 6-8), que lo fecha en época imperial sin más precisiones dentro de una adecuación a las fases generales de la ciudad. Volutas similares parcialmente documentadas aparecen asimismo en el siglo II en el templo denominado N2 en Side: Müfid Mansel, A., 1947 Senesi Side kazilarina dair Önrapor (Vorlaenfiger Bericht über die Ausgrabungen in Side im Jahre 1947), Ankara, 1951, p. 21, con documentación más precisa que Müfid Mansel, A., Die Ruinen von Side, Berlín, 1963, p. 86. Otros ejemplares interesantes de capitel compuesto en Asia Menor no documentan las volutas: Naumann, R., Der Zeustempel zu Aizanoi, Berlín, 1979, Taf. 52.

${ }_{19}$ Hoffmann A., Das Gartenstadion in der Villa Hadriana, Mainz 1980, Taf. 54.1-2; 55.2-3, si bien se trata del kymation de tipo Bügelkymation.

20 Bingöl, $n .^{\circ} 44$ sobre la presencia del kyma lésbico en los modelos de Hermógenes en Magnesia; $n$. 49 (Afrodisias), 80-81 (templo de Antinoo en Claudiopolis) 6297 (templo de Dionisos en Teos) como más representativos. No hay una documentación regional similar para capiteles compuestos o corintios. En capiteles compuestos se documenta la aplicación del kymation jónico en el ábaco en el templo de Zeus de Aizanoi.(Naumann, loc. cit.). No obstante este elemento es bastante más frecuente en ábacos de capiteles tanto jónicos como corintios de todo tipo, y esta aplicación no resulta significativa. 


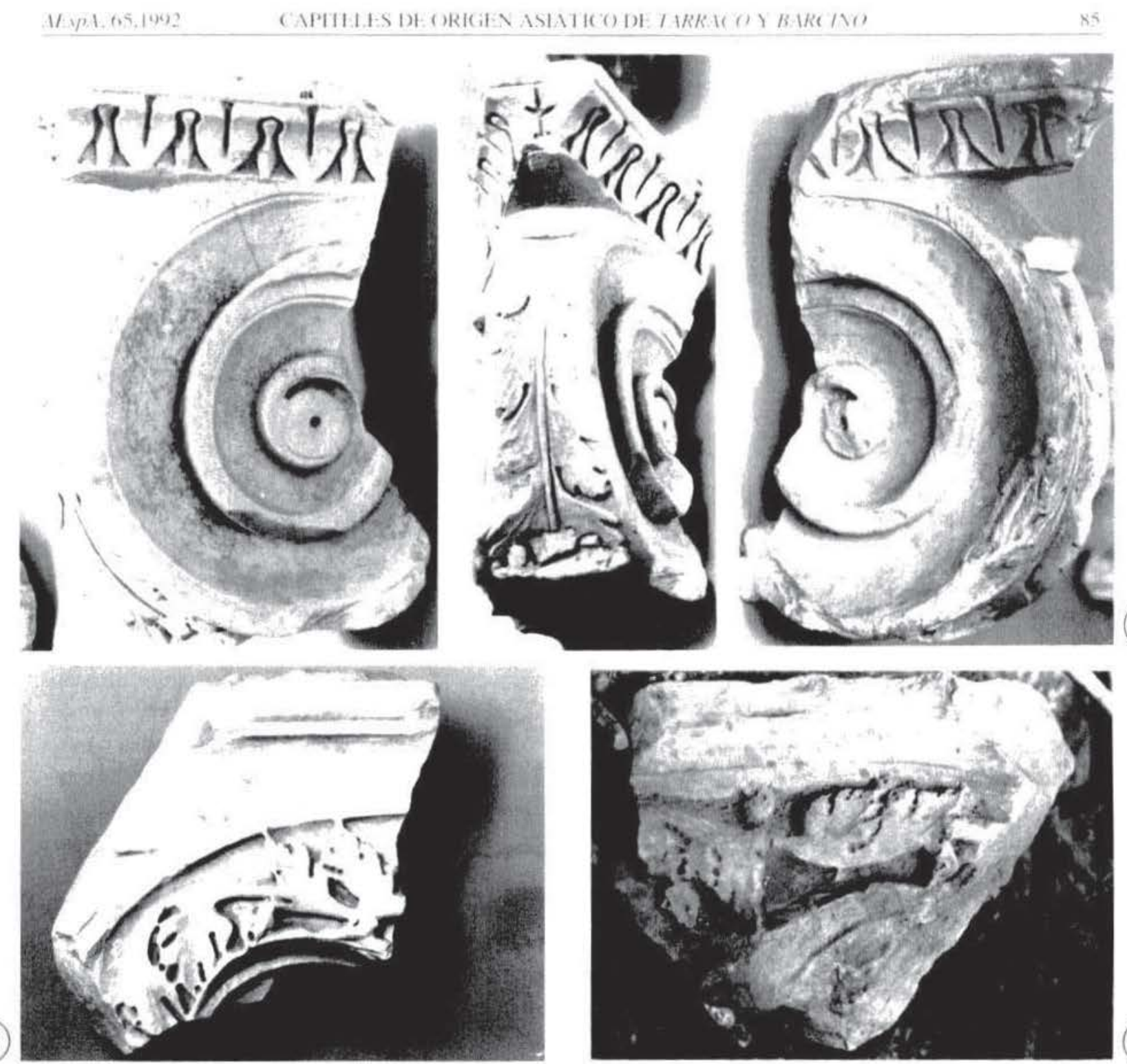

Figura 5.-Tarragonat. Fragmentos de capitel compuesto, grupo 2, números 17 a 19.

kymation utilizado, por último, es el más frecuente en Tarraco, donde aparece con variantes diversas en gran cantidad de fragmentos; ninguno de ellos, sin embargo, corresponde a un capitel, y, por otra parte, la documentación sobre los mismos es bastante deficiente. Únicamente puede ser de utilidad, por existir un mínimo de datos, su aplicación como marco en los relieves decorativos con temática de candelabros - y eventualmente trofeos - conservados fragmentariamente en el MNAT ${ }^{21}$. Este conjunto, no estudiado aún de forma precisa, debe corresponder

21 Pueden contarse 20 fragmentos: consta el n. inv. de tres de ellos, 248, 249 y 12.234. la procedencia de dos y la noticia de procedencia de otra pieza no localizada.

22 Con la reserva de indicaciones más precisas en un estudio en preparación sobre estos fragmentos. deben corresponder a 8 placas como mínimo, de una altura aproximada entre 120 y $140 \mathrm{~cm}$. deducible de la posible altura de los candelabros (cf. Cain, H. V., Römische Marmorkandelaher, Mainz 1986 para tipologías de éstos), con características escultóricas del siglo II más bien avanzado y temática observada en 
a una serie de paneles o placas fechable en el siglo II ${ }^{22}$ y situable en alguno de los recintos de la ciudad alta ${ }^{23}$. El tipo de kyma aplicado, con diversas variantes también - se confirma asimismo la posibilidad de aplicación de diversas variantes en un mismo conjunto decorativo- es asimilable al del ábaco estudiado si bien corresponde visiblemente a otras manos o a otro taller. Dada la profusión de este tipo en Tarraco, este elemento sólo puede tener actualmente un valor relativo. No obstante, la vinculación directa de la voluta a corrientes minorasiáticas del siglo II constituye un dato del mayor interés.

La segunda de las piezas de este grupo (núm. 18) corresponde a un fragmento de canal, voluta y ábaco de un capitel compuesto de mármol. En lo que puede apreciarse de la voluta, presenta una sección también significativamente más plana que los ejemplares del primer grupo y un listel, plano y fino, que la enmarca. No se advierten otros detalles del trazado dadas la exigüidad del segmento conservado y la erosión parcial del borde. Con todo, es interesante observar, en contraste con el ejemplar anterior, la decoración del canal con zarcillos vegetales de hojas presumiblemente acantiformes que alternan su orientación hacia ambos lados del eje o vástago central. Los contornos, cuyo esquema de realización mediante trépano es especialmente visible en los segmentos inacabados, y el modelado plano en escaso relieve sugieren una correspondencia a corrientes del siglo II, y en todo caso diferentes de las observables en el primer grupo. Lo mismo puede decirse de la naturaleza y disposición del propio motivo, que presenta una diferencia sustancial con los zarcillos de los ejemplares de tradición flavia considerados anteriormente. El ábaco es en este caso liso, moldurado, con una secuencia de caveto, listel y medio bocel. Es importante observar que el canal se solapa con la superficie del ábaco. La superficie superior del mismo, por último, presenta un cuadrado portante - scamillus-de 1 centímetro de altura. Esta morfología del ábaco responde asimismo a esquemas identificables en capiteles orientales de época imperial. Heilmeyer documenta numerosos ejemplos en capiteles compuestos del siglo II de Efeso y Afrodisias, y asimismo alguna aplicación en Roma en época de Adriano o posterior ${ }^{24}$. Parece pues corresponder a una obra monumental relacionada con las corrientes de adopción de formas orientales durante el siglo II.

Dos de los fragmentos (núms. 19 y 20) presentan una estrecha analogía con el anterior. Ambos se conservan en el MNAT sin documentación alguna. Corresponden asimismo a sendos segmentos de canal, ábaco y, en uno de los casos (núm. 19), un pequeño sector de voluta, y su grado de erosión es sensiblemente mayor que el de la pieza número 18. Sus características son en esencia equivalentes a ésta, pero pueden aportar tres datos de interés. En primer lugar, la pre-

Roma desde finales del siglo I (Durry, M., Les trophées Farnèse, MEFRA 39, 1921-1922, pp. 303-318; Von Blanckenhagen, P. H., Flavische Architektur und ihre Dekoration, Berlín, 1940, pp. 64-65; Toebelmann, F. Römische Gebälke, Heidelberg 1923, p. 54; Rotili, M. L'arco di Traiano a Benevento, Roma, 1972, pp. 62-65) y especialmente en relieves del Panteón (De Fine Licht, K., The Rotunda in Rome, Arhus, 1966, p. 83).

${ }^{23}$ A través de la procedencia de uno de los fragmentos de la Plaza del Rovellat, hallado en las excavaciones de 1971 (Berges, M., Columnas romanas y cruces visigóticas en la Plaza del Rovellat de Tarragona, Miscelánea Arqueológica, Barcelona 1974, vol. I, pp. 135-168 (pp. 164-165), y de otro, e hipotéticamente un tercero no identificado, reutilizados en el lienzo de la muralla adyacente al antiguo Matadero (Serra Vilaró, J., La muralla de Tarragona, AEA, 76, 1949, pp. 221-236, fig. 11).

${ }^{24}$ Heilmeyer, pp. 94-98. También Bammer, loc. cit., y Strocka, loc. cit. Sobre ejemplares de aplicación en Roma en época de Adriano, Heilmeyer p. 75. 

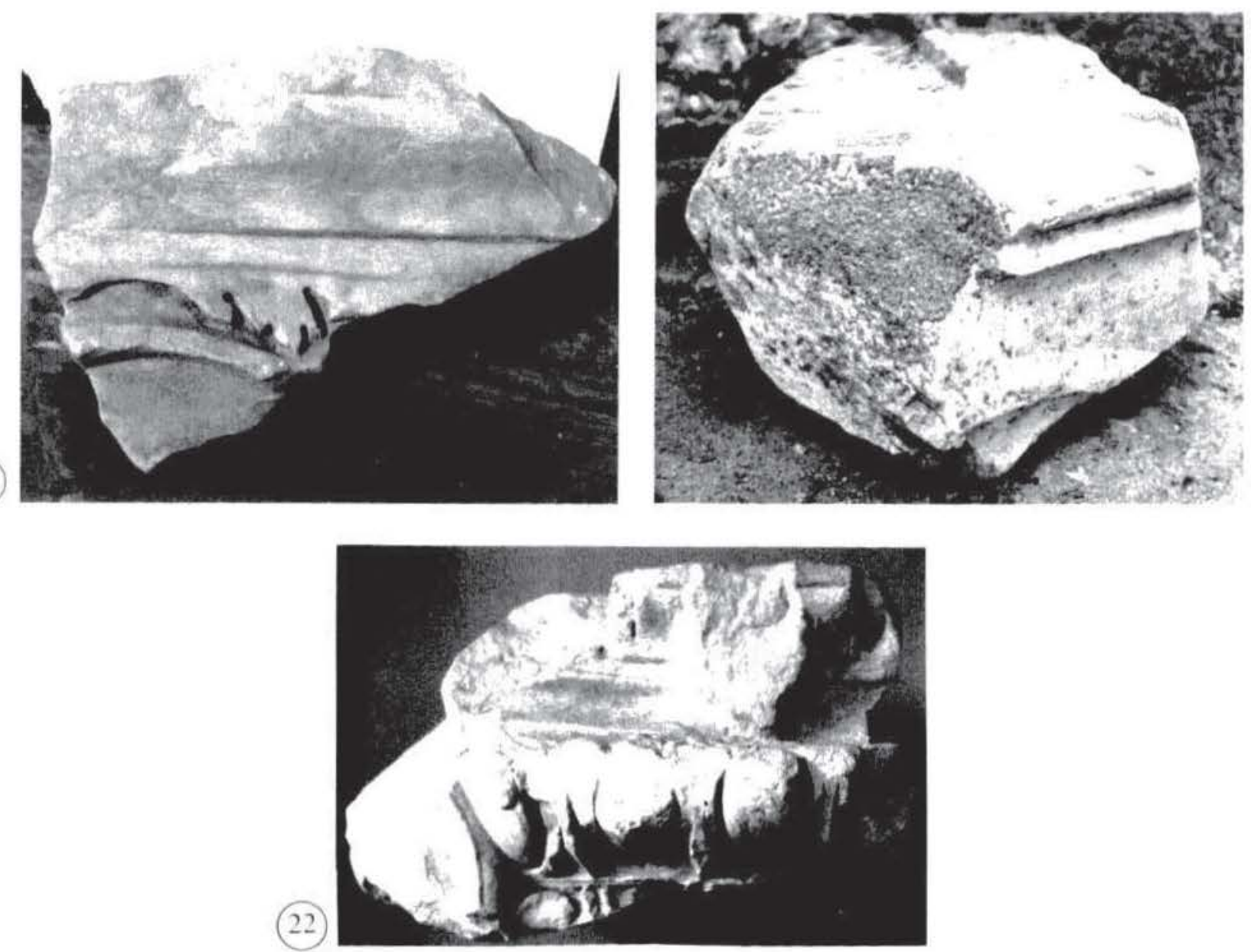

(23)
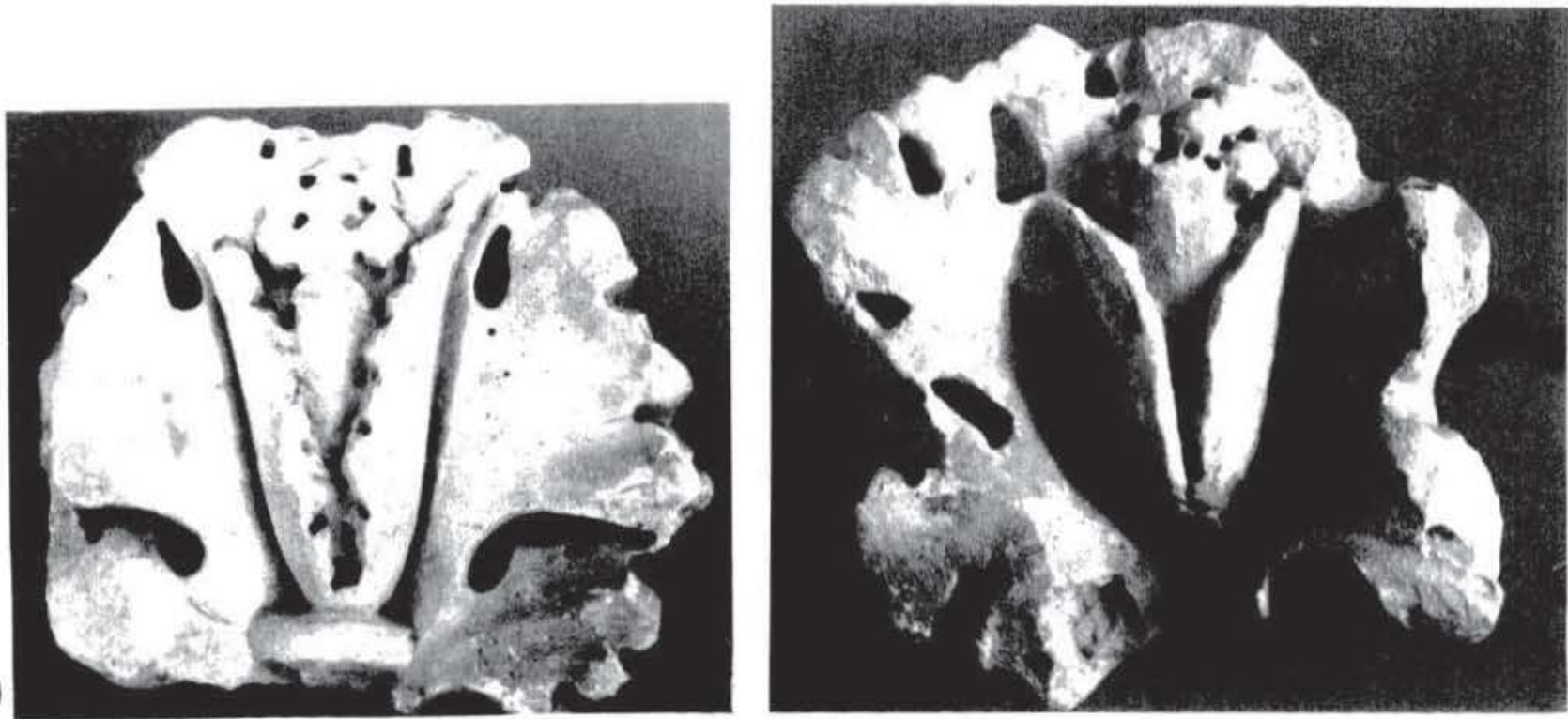

Figura 6. - Tarragona. Fragmentos de capitel compuesto, grupo 2, números 20 a 24. 
Figura 7.- Tarragona, area del foro de la ciudad baja. Fragmento de capitel corintio asialico. MNAT., 5443.

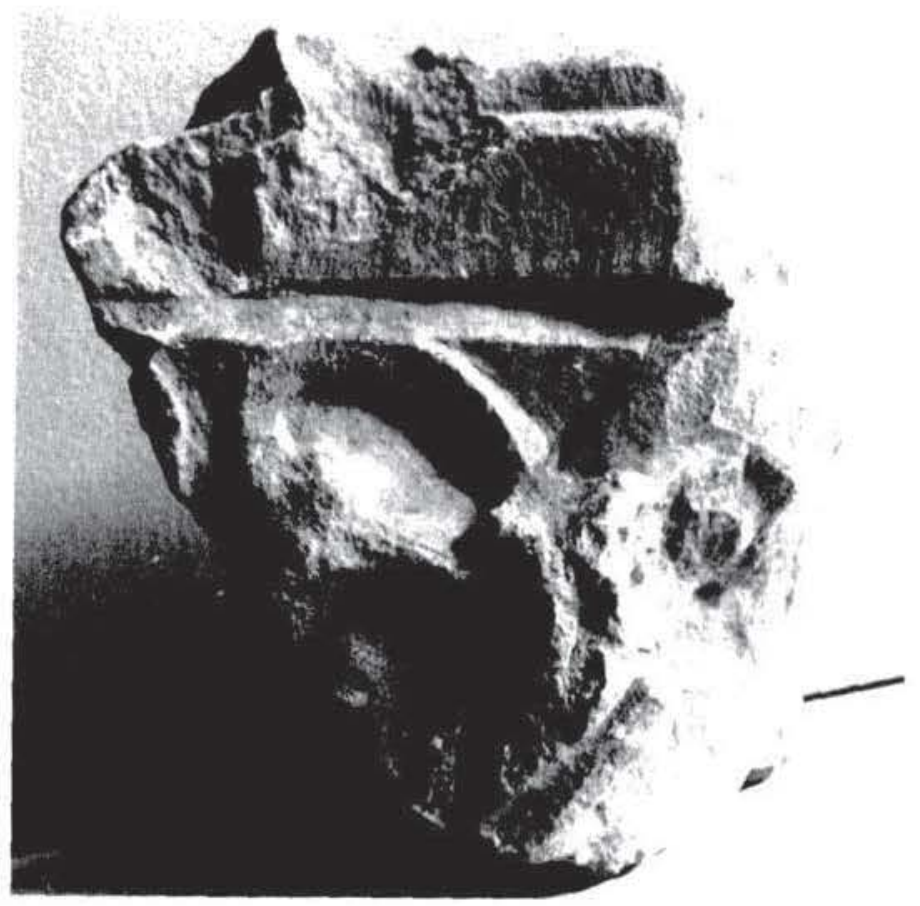

sencia de ligeras variantes de los tipos vegetales, patentes sobre todo en las pequeñas hojas que complementan la composición de los zarcillos en la pieza número 19. En segundo, un acabado incompleto de esta misma pieza, observable en las huellas no borradas de los instrumentos de modelado y en los contornos de los elementos vegetales que permiten apreciar los indicios del trabajo del trépano mejor que en el fragmento número 18 . Y por último la molduración probable del ábaco de la pieza número 20 en cyma reversa, quizá enmarcada por un listel, mientras que el de la número 19, con las reservas debidas a la conservación parcial, sigue la misma secuencia que la anterior. Si bien el resultado visual es en ambos casos equivalente, y desde este punto de vista puede considerarse una variante sin excesivo significado, debe observarse que la aplicación de la cyma reversa es muy frecuente en Tarraco por to menos desde principios de la época flavia: el mejor ejemplo viene constituido por los capiteles toscanos y el arquitrabe de la plaza del foro provincial, conservados en la torre de Pilatos y en un edificio de la plaza del Pa$\mathrm{Hol}^{25}$. Esta variante ofrece por ello connotaciones interesantes.

Un nuevo fragmento (núm. 21), correspondiente al ábaco y un escaso segmento de voluta de un capitel, se encuentra en la entrada a los servicios del Paseo Arqueológico. La altura del ábaco parece indicar un ejemplar de dimensiones considerables, por lo menos en relación con los demás ejemplares registrados. Su molduración es de caveto, listel y medio bocel. Presenta un scamillus en la superficie superior de 2 centímetros de altura, es decir, el doble que el del número 18. Por otra parte, el ángulo que forman las prolongaciones del lado de éste y de la tangente al contorno del ábaco en cualquiera de los puntos del segmento conservado permite comprobar en este ejemplar que, efectivamente, se trata de capiteles compuestos y no jónicos, detalle que no puede comprobarse con esta seguridad en los tres anteriores.

25 Cf. Gimeno, J., Tipología y aplicaciones de elementos dóricos y toscanos en Hispania: el modelo del NE, AEA 62, 1989, pp. 101-139 (pp. 127-131). 

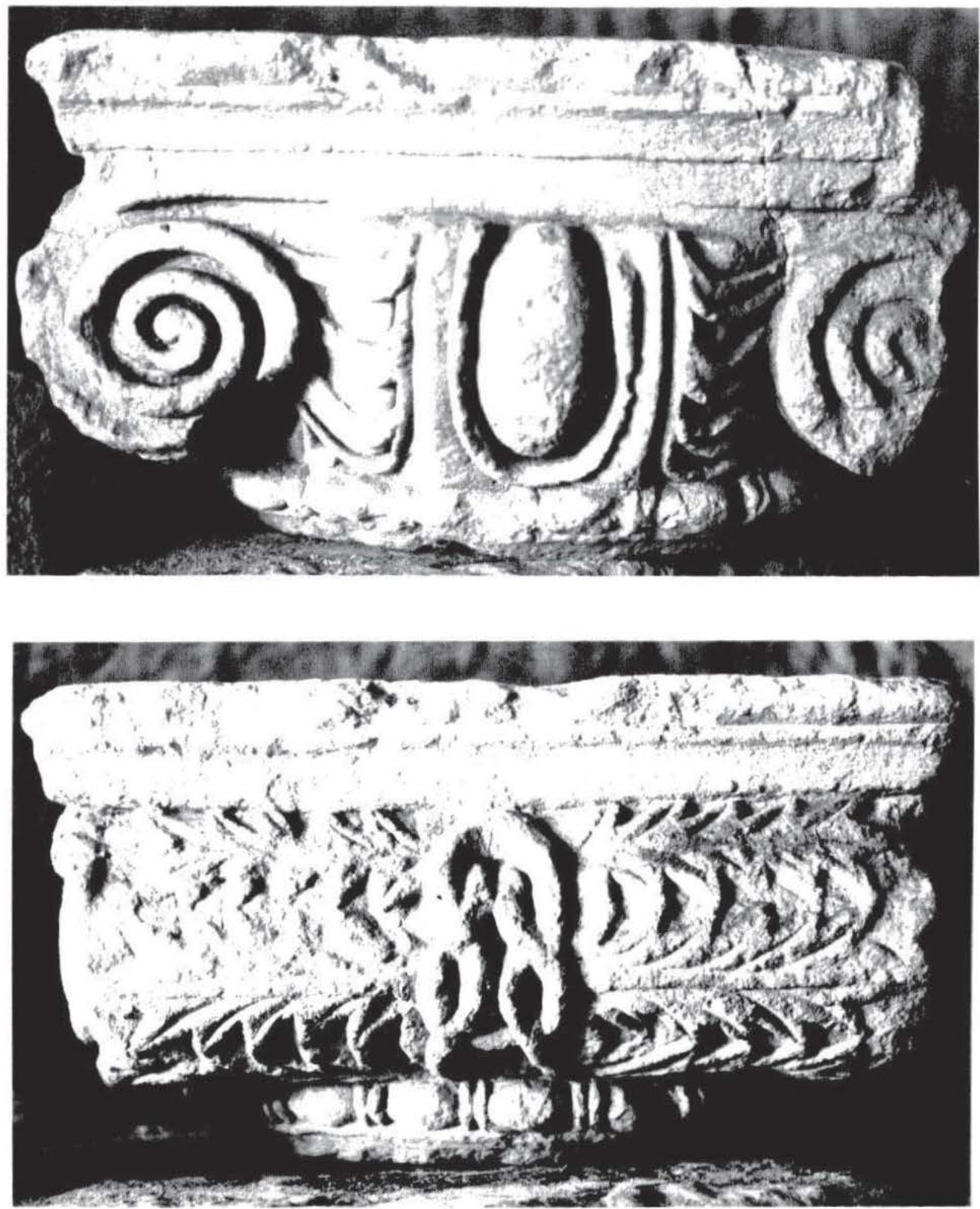

Figura 8. - Barcelona, plaza de la Catedral. Capitel jónico. Museo de Historia de la Ciudad. 
El fragmento número 22 conserva parcialmente los elementos esenciales de la zona jónica del capitel: en concreto, un segmento del contrario, del kymation - suficiente para comprobar que es de cinco ovas-, del canal, de la voluta y del ábaco respectivamente. Aparece señalado el emplazamiento probable de la flor del ábaco, totalmente erosionada.

El kymation proporciona un elemento valioso de datación, tanto por el número de ovas que alude a la recuperación de modelos helenísticos como por su morfología ${ }^{26}$, y puede proponer una asignación al siglo II. La estructura general, por otra parte, conserva las características del capitel jónico, como por ejemplo la forma del equino o el canal, y probablemente la voluta, exentos de decoración vegetal. La probable presencia de la flor del ábaco, sin embargo, es más propia de modelos compuestos, y raramente se encuentra en tipos jónicos dentro de estas corrientes. Presenta en la superficie superior un scamillus con una elevación de 6 milímetros sobre la superficie del ábaco y un retroceso de 7 centímetros respecto a éste.

Recasens, sin aducir motivo alguno, propone para este ejemplar una fecha de la primera mitad del siglo I d. C. Las características observadas parecen apuntar, no obstante, a los tipos introducidos en época de Adriano, sobre todo a partir de las reminiscencias observadas en el equino. Por otra parte, esta misma morfología puede encontrarse en ejemplares compuestos minorasiáticos del siglo II, en concreto en Éfeso y en Afrodisias ${ }^{27}$, con lo que viene a constituir un ejemplo más de esta vinculación.

Dos últimos elementos interesantes en esta línea son dos fragmentos, conservados en el MNAT, de decoración floral (núms. 23 y 24). Aislados intencionadamente de su soporte original, con toda probabilidad por afán de conservación en alguna reutilización de las piezas, deben interpretarse como flores de ábaco. Así lo indican tanto el trabajo y técnica observables, a pesar de las adaptaciones, en las superficies laterales y posterior, como la propia morfología. Si bien no son idénticos, ambos fragmentos pueden considerarse dos variantes de una misma forma. Presentan un cáliz abierto, en uno de los casos - número 23 - sobre un anillo de base cuya forma sugiere la del caulículo, que contiene a su vez una vaina y el pistilo. El conjunto viene enmarcado por pétalos acantiformes.

Esta tipología difiere esencialmente de lo habitual en flores de ábaco de capiteles corintios de cualquier tipo. Ahora bien, se encuentra claramente adoptada en capiteles compuestos minorasiáticos del siglo II, una vez más de Éfeso o Afrodisias ${ }^{28} \mathrm{o}$, en todo caso, en algunos derivados romanos aunque ya del tipo más tardío denominado corintio asiático ${ }^{29}$. Con la reserva de

${ }^{26}$ Leon, pp. 267-268.

${ }^{27}$ Heilmeyer, pp. 94 y 100, con cinco ovas y flor de ábaco. Sobre la reducción del número de ovas del kymation en los capiteles jónicos minorasiáticos, Bingöl, pp. 43-46. No obstante es un factor muy relativo ya en los ejemplares estudiados por Bingöl, por lo que tampoco puede extrapolarse con suficientes garantías a capiteles no directamente relacionados con éstos. Hecha esta advertencia y considerando los hechos, los ejemplares minorasiáticos de cinco ovas son augusteos o bien del siglo II. La primera posibilidad es difícil de encuadrar en Tarraco dada tanto la ausencia de importación de mármol en esta fase como la forma del capitel. En los ejemplares compuestos nimorasiáticos del siglo II abundan los kymatia de tres ovas. Son sin embargo de cinco los de Aizanoi (Naumann, loc. cit.) y Side (Müfid Mansel, loc. cit.). De todas formas, no debe descartarse totalmente la posibilidad de que el ejemplar tarraconense corresponda a un capitel jónico dentro de esta misma corriente, al modo de los ejemplares romanos de época de Adriano.

${ }^{28}$ Heilmeyer, p. 94, de Éfeso; p. 100, de Afrodisias, en menor grado.

29 Heilmeyer, p. 101. 
la relatividad de una flor de ábaco aislada como elemento de comparación, la especificidad de estos términos proporciona un dato especialmente significativo. Respecto a las dimensiones, es dificil pronunciarse con seguridad dado que no se trata de elementos habitualmente documentados por sí mismos en la bibliografía y que no se documentan otras referencias en el conjunto estudiado pero, en líneas generales, puede afirmarse por to menos que no difiere del resto del conjunto.

La presencia de esos fragmentos es importante ya que pueden asimilarse a tipos muy determinados. En concreto. la vinculación de principio al capitel compuesto y no al corintio normal parece significativa, así como su presencia en el mundo minorasiático a partir del siglo II. Habida cuenta de la ausencia de flores de ábaco conservadas en los demás ejemplares registrados. estos fragmentos constituyen elementos de gran valor que reafirman con bastante evidencia las caracteristicas y corrientes del conjunto.

EI número de fragmentos conservado de este segundo grupo es realmente escaso, y en todos los casos se trata de fracciones muy reducidas de los capiteles correspondientes que proporcionan por lanto una documentación muy limitada de los mismos. Sin embargo, su valor como testimonio es de la mayor importancia. Por una parte, documentan la presencia en Tarraco de una corriente de aplicación del capitel compuesto, y más concretamente de determinadas formas del mismo, hasta ahora inédita. Por otra, sugieren la existencia de una corriente de la arquitectura tarraconense, desarrollada durante el siglo II, que parece vincularse a los talleres minorasiáticos de este siglo. Por último conviene subrayar que, contrariamente al conjunto de época flavia, no corresponden a un esquema unitario o a una misma unidad constructiva que motivase por si sola la importación, sino que se identifican varios conjuntos diferentes e independientes - por lo
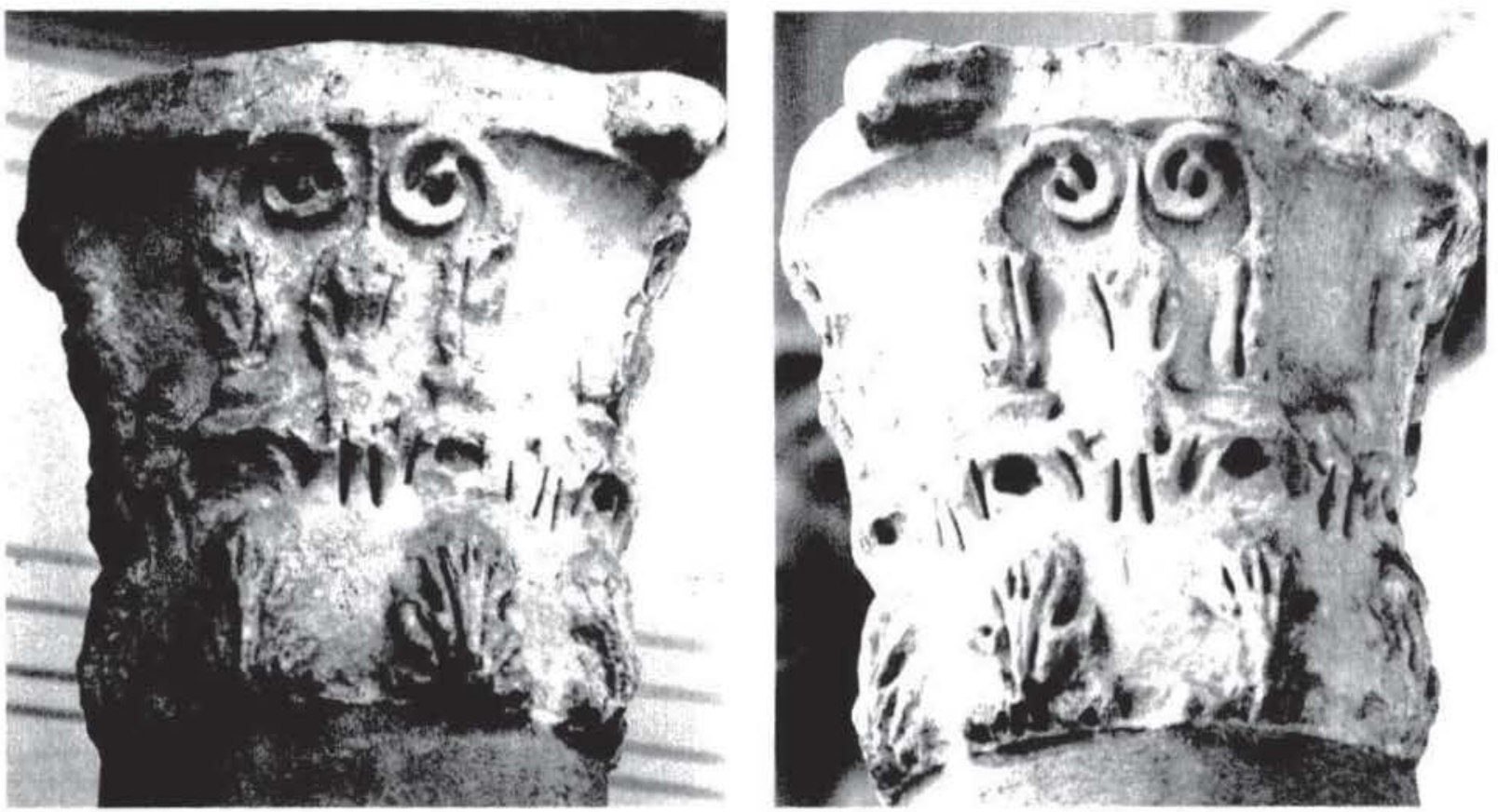

Figura 9.-Barcelona. Capitel corintio. Museo Arqueológico de Barcelona. 19832. 


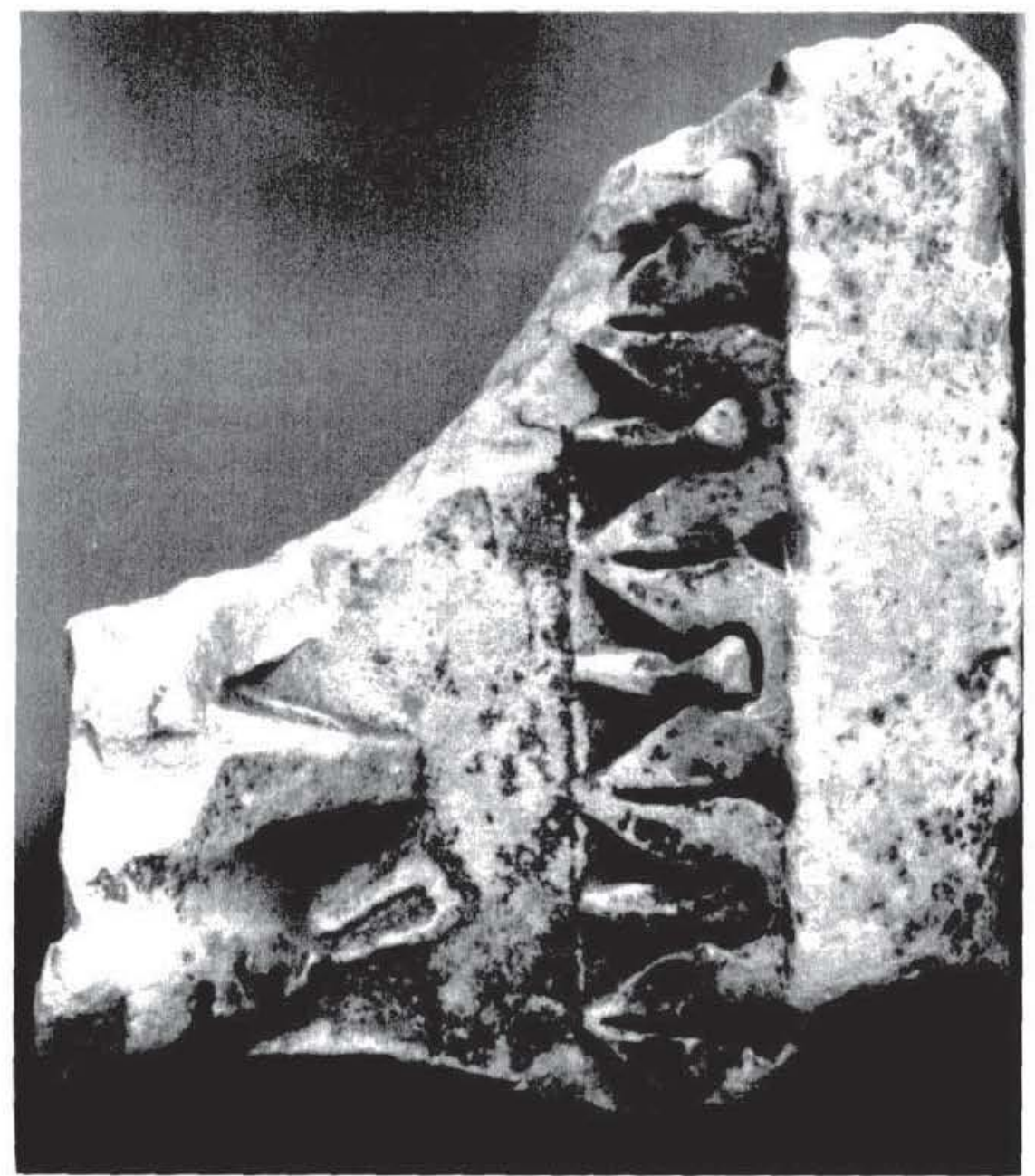

Figura 10.-Tarragona. Fragmento de relieve con tema de candelabros. MNAT.

menos tres - que sugieren más bien una actividad o presencia más dilatada que pudo proveer a diversas edificaciones o programas decorativos. La ausencia de datos de procedencia en la totalidad de los ejemplares impide cualquier hipótesis de asignación en este sentido, salvo los supuestos generales basados en simples similitudes formulados para el ejemplar número 17.

Esta situación plantea varias cuestiones sintetizables, en general, en la forma de relación con Asia o, en sentido amplio, con Oriente, y en el sistema de importación. Estas cuestiones, por otra parte, deben englobarse en la problemática global de la difusión de los talleres minorasiáticos desde el siglo II, que ha sido abordada por diversos autores tanto desde una perspectiva general como referida a determinadas zonas, provincias o regiones del Imperio ${ }^{30}$. La documenta-

30 Principalmene Pensabene, P.. Considerazioni sul trasporto di manufatti marmorei in età imperiale a Roma e in altri centri occidentali, Dialoghi di Archeologia 6, 1972, pp 317-362, que sigue of reciendo el estado de la cuestión general más completo y actualizado, completable en todo caso con los trabajos, de alcance más local, de Pensabene, P. L'importazione di manufatti marmorei ad Aquileia, en Vita sociale, artistica e commerciale di Aquileia romana. Aquileia 1985. Udine, 1987, vol. II, pp. 365-399, Pensabene, P., The Arch of Constantine. Marble samples, en Classical marble, Dordrecht 1988, pp. 411-418 o Pensabene, P., Elementi architettonici in marmo, en Anfiteatro Flavio, Roma, 1988, pp. 53-82. Es tam- 

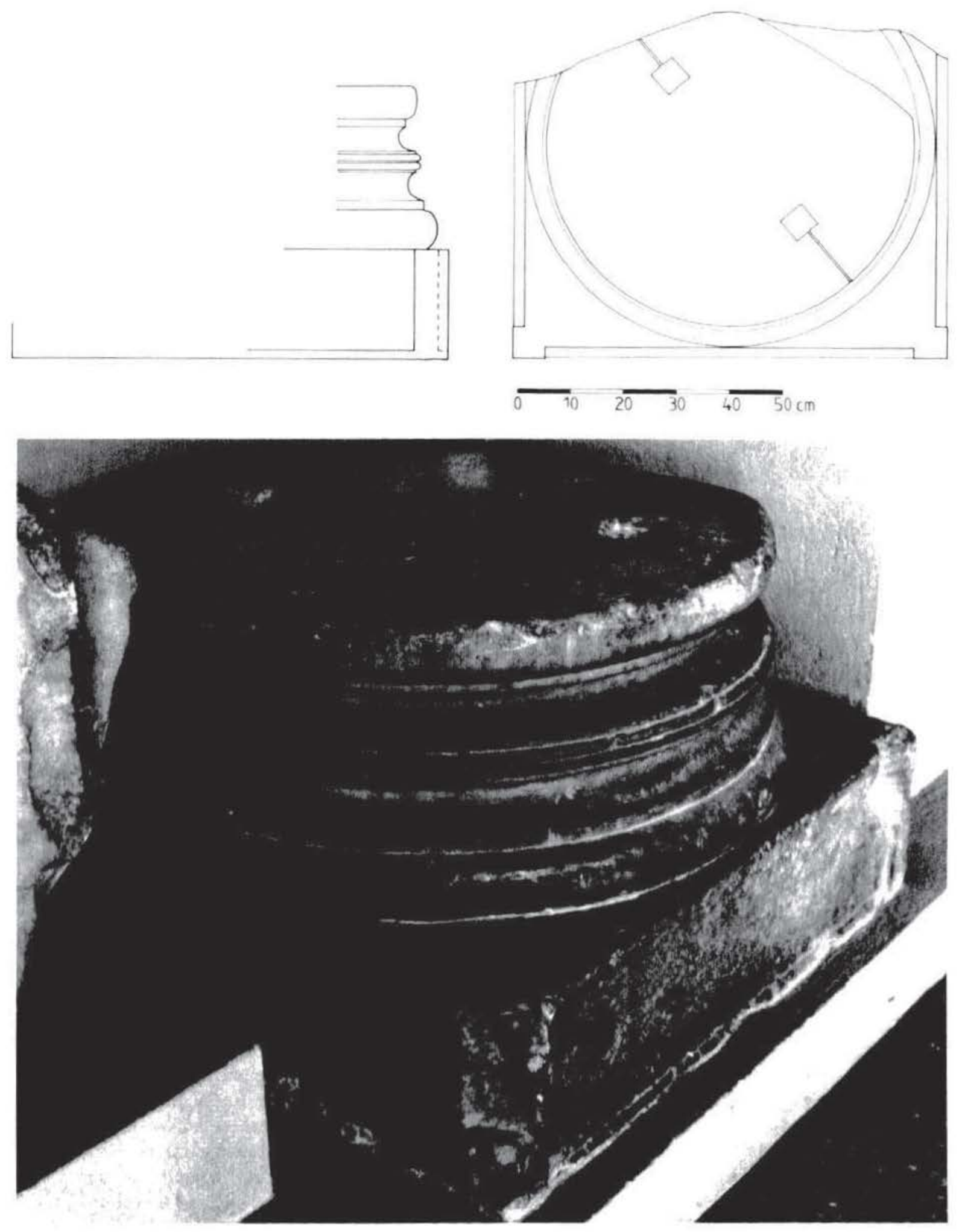

Figura 11.-Tarragona. Basa compuesta. MNAT 99. 
ción de los ejemplares tarraconenses es en este aspecto novedosa, y vendrá a constituir un dato más en la interpretación del problema general y del alcance de esa difusión. Por ello será conveniente repasar las líneas esenciales de la situación de la decoración arquitectónica en Tarraco en el siglo II, en concreto por lo que se refiere a las aplicaciones del mármol en arquitectura representativa, antes de pasar a revisar algunos ejemplares del nordeste de Hispania que pueden ser especialmente útiles.

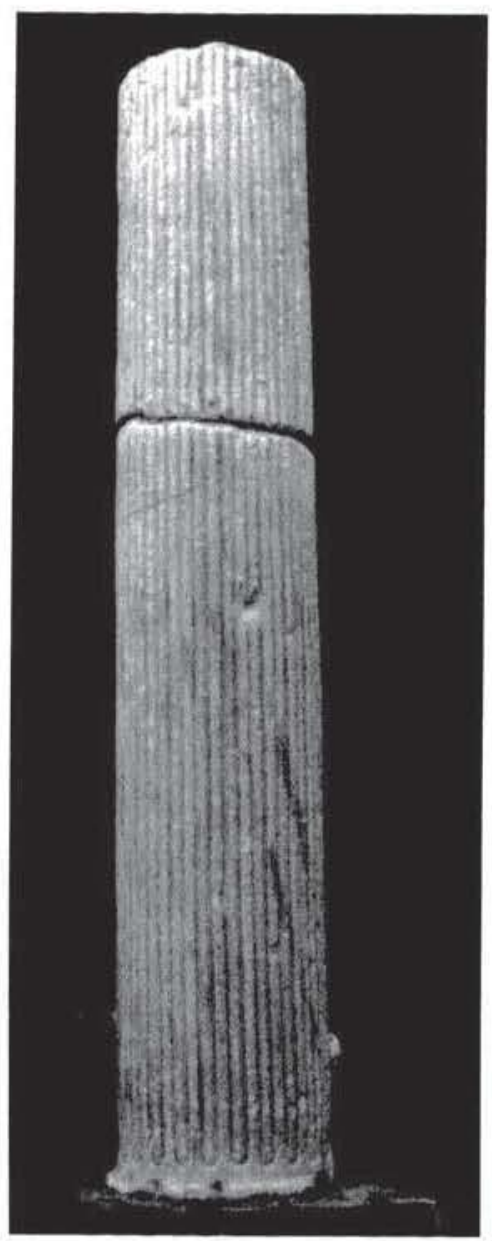

Figura 12.-Tarragona. Fuste de mármol, número 28. Paseo Arqueológico.

bién fundamental Ward Perkins, J., The marble trade and its organisation evidence from Nicomedia, MAAR 36, 1980, pp. 325-338; Dodge, H., Palmyra and the Roman marble trade. Evidence fron the baths of Diocletian, Levant 20, 1988, pp. 215-230; desde el punto de vista formal Heilmeyer, pp. 165-172, completado en Heilmeyer, W. D.. Arte antica e produzione artistica. Lo studio delle officine nell'archeologia classica, Quaderni Urbinesi 28, 1988, pp. 7-26, ó Leon, pp. 238-242, referidos esencialmente a Roma o, más recientemente, Strocka, IM 38, 1988. Referente a África es importante la actualización de Gros, P., Byrsa III. Rapport sur les campagnes de fouilles de 1977 à 1980: la basilique orientale et ses abords. Roma, 1985 (Gros, Byrsa III), especialmente pp. 109-112; cf. también Pensabene, P., Architettura e decorazione architettonica nell'Africa romana: osservazioni, en L'Africa romana, Atti del VI Convegno di Sudi, Sassari 1988. Sassari, 1989, pp. 431-458. 
En Tarraco, la importación de decoración arquitectónica se desarrolla ampliamente desde la época julioclaudia, promovida sin duda por el conjunto monumental que se inicia con la construcción del Augusteum tiberiano y desemboca en el complejo de terrazas de la ciudad alta. Sucede a una fase augustea caracterizada, por lo menos según los testimonios conservados ${ }^{31}$, por una proporción relativamente importante de construcciones monumentales que utilizan exclusivamente material local y cuyos criterios decorativos deben englobarse en las corrientes denominadas provinciales o relacionarse en todo caso con las de los primeros años de la época augustea en Italia central. La actividad julioclaudia, y sobre todo flavia, da lugar a una importante afluencia de mármol y por tanto a un sistema de importación que, según puede desprenderse tanto del material en sí como de la morfología de las piezas, parece organizarse en un esquema de relación exclusiva con estructuras y talleres de la propia Roma ${ }^{32}$. Esta dinámica debe vincularse con el desarrollo de la capitalidad provincial y, en cierto sentido, viene a recuperar y actualizar una tradición tarraconense modificada en la etapa anterior.

En el siglo II, aun sin la intensidad observada en época flavia, se sigue documentando la continuidad de este sistema. Los ejemplos más significativos a este respecto vienen dados por los dos capiteles corintios de tipología relacionada directamente con los del Panteón o la Basílica Ulpia, suponiendo que procedan efectivamente de Tarraco $^{33}$, y otros ejemplares fragmentarios en la misma línea ${ }^{34}$; un conjunto de piezas de cornisa con sima decorada de tradición flavia, procedentes de la ciudad alta y fechables con toda probabilidad en época de Trajano o Adriano ${ }^{35}$;

${ }^{31}$ Principalmente la frons scaenae del teatro (capiteles fechados por Recasens, núms. 16-22 y otros que permanecen inéditos; resto de elementos, Del Arco, A., Hallazgos en el Teatro romano de Tarragona, $B A$ 1919, pp.69-79; Puig i Cadafalch, J. Teatre romá de Tarragona, AIEC 6, 1915-1920, pp. 712-717; Ventura, S. Teatro romano de Tarragona, MMAP 1942, pp. 196-202; otras actualizaciones de la cuestión sobre el edificio no consideran la problemática de la frons scaenae); los tambores de fuste y capitel hallados en la ermita de Els Mongons (Gibert, A. Temples pagans de la Tarragona romana, Tarragona 1916, pp. 109-110), un conjunto de fragmentos de capitel procedentes de la necrópolis del Francolí (Tulla, J. Beltrán, P. Oliva, C., Excavaciones en la necrópolis romano-cristiana de Tarragona, MJSEA 88, 6, 1925 1926, Madrid, 1927, lám. XVII, sin referencias en el texto), un conjunto de capiteles de tipo corintio itálico (Serra Vilaro, J. Excavaciones en la necrópolis romano-cristiana de Tarragona, MJSEA 104, 6, 1928 , Madrid, 1929, p. 53; Recasens 30, 29, 31 y 38), unos fragmentos de cornisa y de friso conservados en el MNAT (Catálogo 119-121 y 313) y otros fragmentos inéditos del MNAT y el Museo Diocesano de Tarragona (MDT) que esperamos publicar en breve.

${ }_{32}$ Cf. Pensabene, Dialoghi di Archeologia 6, 1972, cit., para la organización general de este sistema. $\mathrm{Se}$ integran en el mismo los ejemplares de capitel compuesto que componen el primer grupo. Cf. asimismo Álvarez, A. Mayer, M. Rodà, I., La importación del mármol en época romana. El ejemplo de Ventimiglia y su contraposición con el litoral norte de la Tarraconense, QuadStLun 10-12, 1985-1987, pp. 497 523.

${ }^{33}$ MNAT 34251 y 34252 (Recasens 26 y 27). Efectivamente, no existe ninguna documentación de estas piezas en el MNAT, lo que resulta sospechoso dada la vistosidad de las mismas.

${ }^{34}$ MDT 3385, MNAT 184 y otras piezas $\sin n .^{\circ}$ inv. No son sin embargo tan numerosos como los atribuibles al siglo $\mathrm{I}$.

${ }^{35}$ Fragmentos en el MNAT, n. ${ }^{\circ} 165$ y 12.239 (Catálogo 165; Serra Vilaró, AEA 76, 1949, pp. 221-236, fig. 11) y otros $\sin \mathrm{n} .^{\circ}$ inv. (Morant, J. Hallazgos en el Portal del Carro, BA 1969-1970, p. 125 y otros inéditos), en el MDT y uno en el Museo Arqueológico de Barcelona (Puig i Cadafalch, p. 321), correspondiente a la misma cornisa. En este caso puede establecerse una correspondencia con la ciudad alta por la documentación de la procedencia de cuatro de los fragmentos, de la muralla. 
una basa ática decorada procedente de la calle del Vidrio, asimismo en la ciudad alta ${ }^{36}$, y una basa ática de doble escocia —compuesta- sin procedencia ${ }^{37}$. Debe observarse que estas piezas tienden a situarse en la primera mitad del siglo.

Otros elementos, sin embargo, parecen denotar una transformación del sistema. Ya la mencionada basa de doble escocia sigue un modelo en principio romano, pero que puede encontrarse con características idénticas en otros lugares de ámbito provincial y, en concreto, en el edificio de culto de Itálica, de época de Adriano, que se ha calificado de Traianeum $^{38}$, o en la basílica de Cartago, fechada en el tercer cuarto del siglo ${ }^{39}$. Más significativo resulta un conjunto de fustes monolíticos — por lo menos de tambores muy alargados- de mármol ${ }^{40}$ que presentan una analogía bastante acusada entre sí pero a la vez una heterogeneidad notable de las dimensiones y otras peculiaridades: es decir, parecen poder asignarse a talleres equivalentes pero no corresponden en absoluto a un mismo edificio o conjunto, esquema que ofrece, en principio, una cierta similitud con lo observado acerca de los capiteles compuestos. Es interesante comprobar la presencia de fustes de este tipo, de mármol de Chemtú, en la mencionada basílica de Cartago ${ }^{41}$, y debe advertirse por otra parte que los fustes no son elementos que suelan documentarse habitualmente en la bibliografía, lo que limita bastante las posibilidades de una verificación eficaz. Cabe recordar no obstante los testimonios mencionados por Pensabene sobre el comercio de fustes elaborados completa o parcialmente, a diferencia de otros elementos ${ }^{42}$. No insistiremos, por último, en los relieves con tema de candelabros y trofeos cuyo significado se ha comentado ya en relación con la voluta número 17.

A partir de todo este material parece esbozarse, en el siglo II, una situación más diversificada de los flujos de importación que contrasta con la unicidad de la etapa anterior y, en síntesis, proporciona un contexto bastante preciso a la problemática planteada por los capiteles compuestos estudiados. Es difícil, sin embargo, deducir si esta nueva situación sustituye a la ante-

${ }^{36}$ Mirambell, A. Sancho, P., Nuevos elementos arquitectónicos ingresados en el Museo Arqueológico provincial, $B A$ 1969-1970, pp. 150-152. Fechable a partir de analogías tipológicas bastante precisas con ejemplares romanos: cf. Wegner, M. Schmuckbasen des antiken Rom, Münster 1965, pp. 51-52 y n. ${ }^{\circ}$ $10 \mathrm{~b}$.

${ }^{37}$ MNAT 99: Catálogo 99; Puig i Cadafalch, op. cit., p. 329. Responde en efecto a un modelo muy extendido en Roma a partir del Foro de Nerva (Von Blanckenhagen, P. H., Flavische Architektur und ihre Dekoration. Berlín 1940, p. 16; sobre la evolución más general de basas de doble escocia en Roma, cf. Strong, D. E. Ward Perkins, J. B., The Temple of Castor in the Forum Romanum, PBSR 30, 1962, pp. 130 (pp. 5-12). Se conservan otras basas áticas imperiales de mármol de Tarraco, probablemente relacionables con éstas, pero sin elementos suficientes de datación para proponer una atribución precisa.

${ }^{38}$ León, P., La zona monumental de la Nova Urbs, en Italica (Santiponce, Sevilla). Actas de las primeras jornadas sobre excavaciones arqueológicas en Itálica. Excma. Diputación Provincial de Sevilla, septiembre 1980. (EAE 121), Madrid, 1982, pp. 97-124 o León, P., Traianeum de Italica, Sevilla, 1988, que atribuye esa denominación sin elemento alguno que la justifique.

${ }^{39}$ Gros, Byrsa III, pp. 72 y 95-96. Se trata de un ejemplar, no obstante, de perfil ligeramente más simple que el tarraconense.

40 Pueden registrarse por lo menos ocho ejemplares. Se trata de fustes de 24 acanaladuras con relleno convexo hasta una determinada altura. La mayoría de ellos inéditos. Cf. solamente, como noticia, Balil, A., Excavaciones en la Torre de Pilatos (Tarragona). Campañas de excavaciones de 1962, EAE 65, Madrid, 1969, p. 31; Morant, op. cit., lám. IV; Catálogo 129.

41 Gros, Byrsa III, pp. 59-62.

${ }^{42}$ Pensabene, Op. cit., p. 331. 
rior o, simplemente, se superpone a ella. La cronología de las piezas, en efecto, parece polarizarse, de forma concordante con las dos situaciones identificadas, en torno a dos momentos o intervalos- diferentes, cuyos términos vienen a situar la inflexión entre ambos, es decir, la transformación de las premisas, en época de Adriano. En este punto, y en cualquiera de las dos posibilidades, cabe plantearse si la nueva situación sigue basándose en un papel polar o transmisor de Roma o se pasa a otro sistema de relaciones. Es conocida, en efecto, la presencia de talleres minorasiáticos que trabajan en Roma a partir de la época de Adriano ${ }^{43} \mathrm{y}$, pensando en la hipótesis de una continuidad de la situación anterior, pueden canalizar la nueva aportación a través del sistema ya existente o, en otros términos, actuar de intermediario. En relación con ello es útil recordar que la importación mencionada de piezas monumentales se complementa, precisamente a partir del siglo II, con una intensa afluencia de arquitectura de revestimiento y doméstica en mármoles de diversos tipos y procedencias, que en Tarraco adquiere un volumen sin precedentes. Esta importación se integra en un sistema distinto del anterior que se desenvuelve según otros parámetros, pero interesa señalar su presencia como factor complementario de gran importancia y, dentro de él, advertir la presencia de dos capiteles jónicos de mármol de pequeñas dimensiones, probablemente importados ${ }^{44}$, que dejan entrever un papel de ésta como origen de una corriente de aplicaciones domésticas y por tanto una cierta función de intermediario en esta esfera. Dado el contexto, no obstante, este ejemplo tiene únicamente un valor de referencia.

No obstante, es interesante considerar también el caso de otras provincias, en concreto las africanas. Pensabene identifica al respecto una intensa importación de mármol minorasiático en Tripolitania y Numidia, que tiene lugar a partir de la segunda mitad del siglo Il y que lleva consigo la afluencia de talleres asiáticos que, a diferencia de los que trabajan en Roma, son itinerantes ${ }^{46}$. En Cartago se documenta, precisamente a través de capiteles compuestos, la coexistencia de esos talleres con corrientes procedentes de Roma ${ }^{47}$. También en África se ha observado la restricción de la importación de mármol a las ciudades costeras frente a un desarrollo local de los tipos que predomina en el interior ${ }^{48}$. Estos datos y, especialmente, la ausencia absoluta de una tradición importadora anterior que implica una implantación minorasiática directa, ofrecen gran interés porque suponen un modelo y una aplicación geopolítica diferente de la anterior y, por tanto, otra vía posible de penetración distinta de la mediación romana. Debe señalarse que en todos estos conjuntos, y ya a partir de las observaciones generales de Pensabene basadas en algunos indicios en las canteras y en la ausencia de pruebas en contra, se excluye

${ }^{43}$ Heilmeyer, pp. 165-172; Leon, pp 238-242.

${ }^{44}$ MNAT 135 (Recasens 4) y otro fragmento inédito y $\sin n .^{\circ}$ inv. No se documenta la procedencia de ninguno de los dos.

${ }^{45}$ Hoffmann, Op. cit., pp. 14-15.

${ }^{46}$ Pensabene, Op. cit., pp. 324-325.

${ }^{47}$ Gros, Byrsa III, pp. 109-110; Harrazi, N., Les chapiteaux de la grande mosquée de Kairouan, Tunis, 1982, pp. 57-64, que registra capiteles compuestos de ambas corrientes, realizados tanto en mármol proconesio como de Chemtú. Cf. también Ferchiou, N., Un atelier itinérant de marbriers le long des côtes de Proconsulaire, Antiquités Africaines 19, 1983, pp. 75-84.

48 Pensabene, $O p$. cit. Son de interés las observaciones sobre la evolución progresiva de la explotación local, que se superpone a la anterior probablemente debido a un crecimiento importante de la actividad a partir de la segunda mitad del siglo II, en Ferchiou, N., Une carrière régionale en Afrique: la pierre de Keddel, $R M$ 83, 1976, pp. 367-402. 
unánimemente una importación de las piezas ya elaboradas — salvo fustes-, y se opta por el traslado de los talleres, en principio junto con el material, a los lugares de construcción.

Respecto a los ejemplares de capitel compuesto y a su elaboración, no debe descartarse pues en Tarraco una situación similar a la de Roma, originada o no a través de ésta, o a la de los modelos africanos. En este punto será útil la consideración de tres ejemplares que podrán aportar datos del mayor interés para la comprensión del tipo de importación y los límites de la misma. El primero de ellos es un nuevo fragmento de capitel de mármol de dimensiones monumentales, procedente del foro de la ciudad baja de Tarraco e inédito ${ }^{49}$, correspondiente con cierta probabilidad al tipo denominado corintio asiático. De ser así puede fecharse con facilidad, dado que la difusión de este tipo parece seguir unos límites muy precisos, a finales del siglo $\mathrm{III} —$ como mucho la segunda mitad - o principios del IV. No pertenece al edificio basilical conservado, realizado en material local dentro de corrientes provinciales de época julioclaudia, sino que debe corresponder a una reedificación de cierta importancia en el espacio foral. Pensabene considera este tipo de capiteles como primer testimonio efectivo de la exportación de piezas manufacturadas desde Asia Menor, que en principio sustituye al sistema anterior ${ }^{50}$. El ejemplar tarraconense, único de este tipo en la ciudad y en el NE de Hispania, puede documentar tanto su presencia en $\mathrm{Ta}$ rraco como la continuidad de la participación de ésta en una evolución de las corrientes de importación homóloga a la observable en otras provincias y, particularmente, en África.

Los otros dos ejemplares proceden de Barcelona. El primero de ellos es un capitel jónico de arenisca de Montjuic, también inédito, hallado en la plaza de la Catedral ${ }^{51}$. Entre sus características es interesante observar un equino de notable desarrollo en altura, de tres ovas en principio pero con marcado contraste entre la inhibición de las laterales por medio de las palmetas de ángulo y la presentación clara y completa de la central, bien modelada y enmarcada por cáscara ceñida. Esta morfología parece concordar con corrientes del siglo III o posteriores. Las volutas, de tres vueltas y con el polo en un plano situado aproximadamente a la mitad de la altura del equino, destacan notablemente el borde, que se convierte en el elemento que define la configuración mediante un único efecto de claroscuro y ocupa la totalidad de la altura del canal. Esta resolución es bastante original, por lo menos entre ejemplares documentados, pero puede encontrarse ya en capiteles minorasiáticos de época adrianea, como por ejemplo los correspondientes a la reforma del templo de Dionisos en Teos y algunos ejemplares de Afrodisias, que precisamente añaden una presentación completa de las ovas ${ }^{52}$. El cojinete, por su parte, presenta tres hojas polilobuladas y un balteo con motivo de nudo de Heracles, motivo que aparece en Asia Menor, en concreto en Pérgamo en época de Adriano ${ }^{53}$, y no se documenta en cambio en los conjuntos conocidos occidentales ${ }^{54}$. El ábaco, por último, presenta una molduración en ca-

\footnotetext{
${ }^{49}$ MNAT 5443. Altura $22 \mathrm{~cm}$., medidas horizontales $20 \times 16 \mathrm{~cm}$., altura del ábaco $7 \mathrm{~cm}$.

so Pensabene, Op. cit., pp. 337-339.

${ }^{51}$ Museo de Historia de la Ciudad sin n. ${ }^{\circ}$ inv. La procedencia debe deducirse de Durán i Sanpere, A., Noticia y guía de las excavaciones de la calle Condes de Barcelona. Foro romano, basílica paleocristiana y edificaciones posteriores, Barcelona $1954, n .{ }^{\circ} 41$. Altura $31 \mathrm{~cm}$, altura del equino $13 \mathrm{~cm}$., altura del collarino $3 \mathrm{~cm}$., altura del ábaco $6,5 \mathrm{~cm}$., diámetro de las volutas $13 \mathrm{~cm}$., diámetro de base $41 \mathrm{~cm}$., longitud del cojinete $50 \mathrm{~cm}$., ábaco $56 \mathrm{~cm}$.

${ }^{52}$ Bingöl, pp. 55-61 (Afrodisias) y 296 (Teos).

53 Bingöl, p. 62.

54 Pensabene, P., Scavi di Ostia, VII. I capitelli. Roma, 1973, pp. 37-52.
} 
veto, listel y medio bocel, equivalente a la observada en los fragmentos de capitel compuesto tarraconenses. Con las reservas debidas a la escase $z$ de ejemplares y sobre todo de conjuntos completos documentados, este modelo parece inscribirse dentro de las corrientes de aplicación del capitel jónico en piezas de pequeñas dimensiones — domésticas- derivadas en segunda fase de modelos monumentales asiáticos que se desarrollan a partir de la época de Adriano pero, dentro de ellas, debe vincularse más a tipos propiamente minorasiáticos que a aplicaciones romanas u occidentales. Es interesante contrastar esta particularidad, que bien puede responder a la presencia de un taller o artífice minorasiático, con la evolución del capitel jónico de aplicación doméstica en Tarraco en este mismo período que, probablemente a partir de modelos iniciales importados, desarrolla una tipología local independiente de otras influencias ${ }^{55}$.

Mayor interés ofrece un capitel corintio de columna de arenisca de Montjuic conservado en el Museo Arqueológico de Barcelona ${ }^{56}$. Algunos de sus elementos, como las volutas o la posible decoración del ábaco, han sido eliminados completamente en una reutilización como pila. Pero en cualquier caso puede advertirse que se trata de un ejemplar original en el conjunto de capiteles barcinonenses. Se le ha querido atribuir una cronología flavia a partir de la observación de las hojas y mediante el habitual argumento del trépano y las zonas de sombra ${ }^{57}$. El tipo del acanto, en primer lugar, puede derivar aparentemente de la evolución de modelos romanos de época julioclaudia pero, sin embargo, los vacíos sobre el propio eje de las hojas —comparables en este punto con las del anthemion de la cornisa tarraconense mencionada anteriormente- y la importancia concedida al modelado en surcos determinan una diferencia significativa. Además, es de suma importancia en este caso analizar más detalladamente la zona superior. En concreto las hélices, de sección muy estrecha, probablemente cóncava con borde aunque no puede definirse con precisión, describen espirales muy abiertas con polo indefinido y, a su vez, dejan vástagos radiales que unen puntos correspondientes de vueltas consecutivas, probablemente para evitar los problemas de fractura que podría presentar hipotéticamente el vaciado total. No obstante, la arenisca de Montjuic no tiene por qué presentar estos problemas, como puede indicar por ejemplo el profundo modelado de las volutas del ejemplar jónico anterior. Es interesante asimismo observar las proporciones, muy estilizadas, de los cálices y de los tallos de las flores del ábaco, así como el modelado acantiforme con importantes surcos verticales de trépano tanto en los primeros como en los cálices en que apoyan los segundos. Esta resolución, tanto de cada uno de los elementos como del conjunto, es significativa ya que se diferencia claramente de las corrientes locales y occidentales, mientras que puede encontrarse con analogías muy precisas en algunos conjuntos orientales. Weigand, en un trabajo clásico que estudia precisamente estas diferencias, documenta ejemplos con estas soluciones del modelado de los cálices en Éfeso, de éstos y el cáliz del tallo de la flor del ábaco en Éfeso y Mileto, o de las hélices en Alejandría — como antecedente- y Baalbek ${ }^{58}$. Varios de estos ejemplares, en concreto de

${ }_{55}$ Recasens, pp. 5-15.

56 Museo Arqueológico de Barcelona 19832. Altura $58 \mathrm{~cm}$., altura de la corona inferior de acanto $17 \mathrm{~cm}$., altura de la corona superior $30 \mathrm{~cm}$., altura del ábaco $8 \mathrm{~cm}$., diámetro de base $48,5 \mathrm{~cm}$., máximo conservado de la longitud del ábaco (no diagonal) $75 \mathrm{~cm}$.

57 Gutiérrez, M. A., Capiteles de Barcino en los museos de Barcelona, Barcelona, 1986, n. 21.

${ }^{58}$ Weigand, E., Baalbek und Rom, die römische Reichkunst in ihrer Entwickelung und Differenzierung, JDAI 29, 1914, pp. 37-91, n. ${ }^{\circ}$ 13B2 y 17 (p. 60) de Éfeso, 14B2 de Mileto, p. 41 de Alejandría, 13B2, 14B2, 15B2, 17 y 24B4 de Baalbek. 
Baalbek, presentan precisamente la solución de los vástagos radiales de unión de las vueltas de las hélices. Si responden a criterios técnicos, como parece probable, deben vincularse pues a tradiciones orientales quizá originadas por un tipo de material y sugerir, como hipótesis, una aplicación inicial en Barcino, resultante de esta tradición, en un ejemplar tan directamente relacionado con los tipos orientales. Por otra parte, los capiteles asiáticos mencionados se fechan en su totalidad en el siglo II, y se diferencian claramente tanto de los del 1 en la misma región como de la tradición romana, por lo que suponen una referencia bastante precisa. Pueden añadirse, con análogas observaciones, ejemplares de Pérgamo del siglo II registrados por Heilmeyer ${ }^{59}$. Volviendo, tras estas observaciones, a los acantos, puede comprobarse fácilmente que los tipos correspondientes a la derivación observada aparecen también en los ejemplares referidos: análogo gusto por el modelado en surcos y una cierta separación de foliolos se encuentran, por ejemplo, en ejemplares de Éfeso y Baalbek ${ }^{60}$.

Estos ejemplares barcinonenses ofrecen gran interés por estar realizados en arenisca de Montjuic, es decir, en material local, lo que supone una elaboración local de tipos directamente procedentes del mundo asiático y, por tanto, un testimonio efectivo de la presencia de talleres asiáticos que trabajan en la ciudad. Testimonio, por otra parte, de la difusión de estos tipos y estos talleres en los ámbitos monumental y doméstico y fuera de los circuitos de importación de elementos marmóreos. Este hecho no se documenta de manera tan precisa en Tarraco ya que, como se ha observado, todos los elementos de estas características son de mármol importado. Solamente el tipo de kymation lésbico del ábaco de la pieza número 17 o la cyma rever$s a$ aplicada en el de la número 20 pueden suponer, con las correspondientes reservas, indicios de una vinculación a tipos o recursos de aplicación frecuente en la ciudad. La presencia efectiva de talleres orientales documentada en Barcino, junto a los datos de carácter general, hace bastante verosímil una presencia similar, incluso más arraigada, en Tarraco. Por otra parte, los ejemplares de Barcino parecen sugerir asimismo en el nordeste de Hispania una situación diferente al modelo norteafricano en lo que respecta a la relación entre tipo de material y manufactura y a la disociación entre elementos locales e importados. Se mantiene no obstante, por lo menos a falta de testimonios en contra, la restricción de la presencia oriental a las ciudades costeras.

Por otra parte, la diferencia de los tipos registrados en Tarraco y en Barcino permite asegurar la presencia de talleres o grupos de talleres orientales netamente independientes en ambas ciudades. No hay indicio alguno de evolución o transferencia dentro de la región en ningún sentido. A pesar de que la escasez de elementos conservados impide observaciones más precisas, puede proponerse un modelo general de multiplicidad de talleres, incluso de procedencia de los mismos, más que de expansión a partir de un solo centro. Esta multiplicidad puede existir asimismo dentro de una misma ciudad - Tarraco con mayor probabilidad- pero la documentación no permite comprobarlo. A partir de lo observado sobre el capitel corintio de Barcino, las posibilidades de origen no deben circunscribirse necesariamente a Asia Menor -que sigue siendo no obstante el centro por excelencia sino que pueden extenderse a Siria. Por último, la ausencia de elementos arquitectónicos de mármol conservados en Barcino, en contraste con la profusión tarraconense y la situación de las manufacturas observada en esta ciudad, constituye

${ }^{59}$ Heilmeyer, p. 93.

${ }^{\infty}$ Weigand, Op. cit., n. 13B2, 14B2 y $18 \mathrm{~B} 3$. 
un elemento más en la dificultad de apreciaciones precisas. En cualquier caso, la presencia, multiplicidad y extensión de los talleres asiáticos parece fuera de duda.

Los ejemplares analizados, pues, constituyen testimonios que añadir en la interpretación del fenómeno de expansión de los talleres minorasiáticos a partir de la segunda mitad del siglo II. En síntesis, a través del material tarraconense y a partir de unas condiciones iniciales de continuidad del flujo de importación desde la época julioclaudia, puede comprobarse que esta dinámica tiene lugar a partir de la segunda mitad del siglo II, o todo lo más de la época de Adriano, y no anteriormente, y supone un cambio en el esquema de relaciones. No puede deducirse con exactitud, a partir del material conservado, si el nuevo sistema sustituye al aprovisionamiento desde Roma o se superpone al mismo. En todo caso parece perfilarse que la dinámica inicial se prolonga hasta la época de Adriano y que es en ésta cuando tiene lugar en todo caso la transformación de las coordenadas, que se compagina con la organización simultánea de todo un sistema de importación de revestimientos y piezas de tamaño menor dentro del proceso general de divulgación de las aplicaciones marmóreas. Barcino, que hasta entonces había desarrollado su decoración arquitectónica dentro de las corrientes provinciales occidentales, se agrega al nuevo sistema probablemente en relación con el auge que experimenta su vida urbana en el siglo II. En cualquiera de los supuestos, superposición o sustitución, es posible una función inicial de Roma como intermediario a través de los talleres minorasiáticos que instalan en la Urbe, lo que concordaría con las premisas de una evolución sin rupturas de la tradición tarraconense. Sin embargo, el proceso de la importación de mármol en África proporciona una posibilidad, ya sea alternativa o subsiguiente, tanto de configuración como de vía de transmisión del sistema. El material de los capiteles de Barcino, por su parte, atestigua de manera inequívoca la existencia de talleres asiáticos que trabajan en el NE hispano. Ahora bien, la escasez de ejemplares y la neta disociación de los conjuntos impiden comprobar el carácter de estos talleres, es decir, si se trata de establecimientos fijos según el modelo romano, itinerantes según el atestiguado en África, o siguen otro sistema. En cuanto a la evolución posterior, el capitel jónico de la plaza de la Catedral de Barcelona puede constituir, salvando las condiciones de aplicación, el único testimonio probable del trabajo de estos talleres durante el siglo III en un contexto que contrasta con la importación de capiteles corintizantes elaborados o con la evolución en coordenadas locales que se observa en Tarraco. Por último, si se acepta la identificación del capitel procedente de la zona del foro de la ciudad baja de Tarraco como corintio asiático, viene a indicar, de nuevo en un ámbito de arquitectura monumental pública, una prolongación y conclusión del ciclo homóloga a la observada en las demás regiones occidentales, es decir, mediante un nuevo paso a la importación, esta vez segura, de ejemplares elaborados ${ }^{61}$.

${ }^{61}$ Este trabajo se entregó para su publicación en julio de 1990. Con posterioridad a esa fecha han aparecido diversos estudios cuyo contenido puede relacionarse con los argumentos aquí expuestos y que pueden completar, por tanto, la documentación bibliográfica. En primer lugar cabe mencionar nuestra propia tesis doctoral, Gimeno, J., Estudios de arquitectura y urbanismo en las ciudades romanas del Nordeste de Hispania, Madrid, 1991, que recoge y documenta la mayoría de las piezas arquitectónicas de Barcino y Tarraco utilizadas aquí como referencia, bajo los números 36-40, 161-162, 245, 290-299, 375, 509-510, $1208-1221,1224,1235-1251,1272-1276,1289-1299,1420-1426,1442-1443,1556-1558,1585,1621-$ $1641,1668-1670,1673-1747,1889-1898,1913$ y 1960-1967 del catálogo. Las referencias de otros centros y regiones pueden incrementarse con algún ejemplar recogido por Chiner, P., La decoración arquitectónica en Saguntum, Valencia, 1990. Es interesante asimismo, como documentación regional de de- 
terminadas tipologías, el trabajo de Petrova, S., Le chapiteau composite de Mésie et de Thrace, ArcheologijaS of 32, 1990, pp. 8-16. La publicación de Stadtbild und Ideologie. Die Monumentalisierung hispanischer Städte zwischen Republik und Kaiserzeit, München, 1990, actualiza no pocos aspectos de la problemática de las ciudades hispanas. E. Koppel (pp. 328-340) insiste nuevamente sobre los relieves tarraconenses con representación de Zeus Amón (cf. nota 10) y propone para uno de los fragmentos una fecha de finales de la época julioclaudia, cronología que, sin entrar en la discusión, no afectaría en absoluto a las conclusiones de este trabajo, antes bien, integraría más estrechamente esos relieves en la problemática planteada por todos los elementos del conjunto, comprendidos los capiteles compuestos: véase lo observado en la nota 3 y en el propio texto sobre este tipo de precisiones. Interesan también, como referencias generales, los trabajos de A. U. Stylow (pp. 259-282) y H. von Hesberg (pp. 283-288) sobre Cordu$h a$, o el de M. Pfanner ( pp. 59-116) que, entre otras cosas, concuerda con la indefinición aquí apuntada del edificio cultual adrianeo de Itálica. Los aspectos relacionados con el comercio de mármol cuentan con un mayor volumen de trabajos en los últimos años: así Baccini Leotardi, P., Nuove testimonianze sul commercio dei marmi in età imperiale, Roma, 1989, Herrmann, J. J., Thasos and the ancient marble trade. Evidence from American museums, en Marble. Art historical and scientific perspectives on ancient sculpture, Malibu, 1990, o el volumen conjunto específico Il marmo nella civiltà romana. La produzione e il commercio, ed. E. Dolci, Carrara, 1990, en que cabe destacar los trabajos de M. Bonamici (pp. 83-101), el propio E. Dolci (pp. 11-37), F. Olevano et al. (pp. 137-149), o G. Tedeschi Grisanti (pp. 115-125). Debo citar también el volumen conjunto, no recogido en la bibliografía inicial, Ancient marble quarrying and trade. Papers from a Colloquium held at the annual meeting of the Archaeological Institute of America, San Antonio, Texas, 1986, Oxford, 1988. Todos estos trabajos perfilan notablemente la problemática sobre algunas de las cuestiones analizadas en el texto, pero no modifican, antes bien, corroboran los argumentos expuestos. Agradezco al comité de redacción de Archivo Español de Arqueología la oportunidad de añadir esta nota así como las sugerencias formuladas al respecto. 
TARRACO. FRAGMENTOS DE ZONA SUPERIOR DE CAPITEL COMPUESTO DE MÁRMOL

\begin{tabular}{|c|c|c|c|c|c|c|c|}
\hline N. localización & Procedencia & Altura & Longitud & Grosor & $\begin{array}{l}\text { Diámetro } \\
\text { de la } \\
\text { voluta }\end{array}$ & $\begin{array}{l}\text { Altura } \\
\text { del } \\
\text { ábaco }\end{array}$ & Referencia \\
\hline \multicolumn{8}{|l|}{ GRUPO I } \\
\hline 1 MNAT 12238 & $\begin{array}{l}\text { Muralla, zona del } \\
\text { Matadero }\end{array}$ & 25 & 10 & 10 & & & $\begin{array}{l}\text { Serra Vilaró, } A E A \\
\text { 76. 1949, fig. } 11\end{array}$ \\
\hline 2 MDT $\sin n . "$ inv. & Zona de la Catedral & 26.5 & 15 & 9 & & & \\
\hline 3 MDT 565 & Zona de la Catedral & 19,3 & 16 & 10,5 & & & \\
\hline 4 MDT $\sin n, "$ inv. & Zona de la Catedral & 26,5 & 20 & 11 & & & \\
\hline 5 MNAT $\sin n .^{\circ}$ inv. & $\begin{array}{l}\text { Plaza de Rovellat o } \\
\text { del Forum, } 1971\end{array}$ & 20 & 23 & 14 & & & \\
\hline $\begin{array}{l}6 \text { MNAT } 132 \\
\text { (sg. Recasens) }\end{array}$ & No documentada & 32 & 24 & 13 & 32 & & $\begin{array}{l}\text { Catálogo 132-134; } \\
\text { Recasens } 53\end{array}$ \\
\hline $\begin{array}{l}7 \text { MNAT } 134 \\
\text { (sg. Recasens) }\end{array}$ & No documentada & 19 & 26 & 10 & & & $\begin{array}{l}\text { Catálogo 132-134; } \\
\text { Recasens } 54\end{array}$ \\
\hline 8 MNAT $\sin n .^{\circ}$ inv. & No documentada & 33 & 25 & 10 & & & \\
\hline $\begin{array}{l}9 \text { MNAT } 133 \\
\text { (sg. Recasens) }\end{array}$ & No documentada & 36 & 23 & 15 & & & $\begin{array}{l}\text { Catálogo 132-134: } \\
\text { Recasens } 55\end{array}$ \\
\hline 10 MNAT 161 & No documentada & 32 & 24 & 11 & & & $\begin{array}{l}\text { Catálogo 161: } \\
\text { Recasens } 56\end{array}$ \\
\hline $\begin{array}{l}11 \text { MNAT } 234 \\
\text { (sg. Recasens) }\end{array}$ & No documentada & 34 & 21 & 10 & & & Recasens $52\left(^{*}\right)$ \\
\hline 12 MNAT 247 & No documentada & 20 & 11 & 9 & & & $\begin{array}{l}\text { Cutálogo 247; } \\
\text { Recasens 50 }\end{array}$ \\
\hline 13 MNAT 34274 & No documentada & 30 & & 10 & & & Recasens 51 \\
\hline 14 MNAT sin n. inv. & No documentada & 10 & 16.5 & 12 & & & \\
\hline 15 MNAT $\sin n^{\circ}$ inv. & No documentada & 14 & 17,5 & 14 & & & \\
\hline 16 MNAT sin n." inv. & No documentada & 15 & 15 & 15 & & & \\
\hline \multicolumn{8}{|l|}{ GRUPO 2} \\
\hline 17 MNAT 136 & No documentada & 40 & 22 & 12,5 & 32,5 & 7.5 & $\begin{array}{l}\text { Catálogo 136; } \\
\text { Recasens } 49\end{array}$ \\
\hline 18 MNAT $\sin n .^{\circ}$ inv. & No documentada & 32 & 28 & & & & \\
\hline 19 MNAT $\sin n .^{\circ}$ inv. & No documentada & 33 & 36 & 28 & & 9 & \\
\hline 20 MNAT $\sin n .^{\circ}$ inv. & No documentada & 16,5 & 28 & 16 & & & \\
\hline $\begin{array}{l}21 \text { Paseo Arqueolo- } \\
\text { gico, entrada a } \\
\text { servicios }\end{array}$ & No documentada & 29 & 57 & 32 & & 14 & \\
\hline 22 MNAT 34273 & No documentada & 29 & 35 & 25 & & & Recasens 47 \\
\hline 23 MNAT $\sin n^{\circ}$ inv. & No documentada & 18 & 13 & 20 & & & \\
\hline 24 MNAT $\sin n .^{\circ}$ inv. & No documentada & 21 & 19 & 15 & & & \\
\hline
\end{tabular}

Las medidas se dan en cm. Abreviaturas: MNAT = Museo Nacional Arqueológico de Tarragona; MDT = = Museo Diocesano de Tarragona; Referencias: Catálogo = Hernández Sanahuja, B. Del Arco, A., Catálogo del Museo Arqueológico de Tarragona, Tarragona 1894; Recasens = Recasens, M., Los capiteles romanos del Museu Nacional Arqueològic de Tarragona, BA 1979, pp. 43-144; Serra Vilaro, $A E A 76,1949=\mathrm{Se}$ rra Vilaro, J. La muralla romana de Tarragona, $A E A$ 76, 1949, pp. 221-236.

(*) La descripción de Catálogo 234 no parece corresponder a una voluta. Mantenemos no obstante la identificación de Recasens. 